\title{
Magnetic and shape fabrics of magnetite in simple shear flows
}

Laurent Arbaret $^{\left(1^{*}\right)}$, Patrick Launeau ${ }^{(2)}$, Hervé Diot ${ }^{(2,3)}$ and Stanislas Sizaret ${ }^{(1)}$

1- Université d'Orléans, Université François Rabelais - Tours, CNRS/INSU, Institut des Sciences de la Terre d'Orléans - UMR 7327, Campus Géosciences

1A, rue de la Férolerie, 45071 Orléans cedex 2 France

laurent.arbaret@univ-orleans.fr

stanislas.sizaret@univ-orleans.fr

2- UMR CNRS 6112, Laboratoire de Planétologie et Géodynamique, Université de Nantes, rue de la Houssinière, 44322 Nantes

patrick.launeau@univ-nantes.fr

3- Pôle Sciences et Technologie, Université de La Rochelle, Av. M. Crépeau, F-17042 La Rochelle Cedex 01, France

herve.diot@univ-lr.fr

* Corresponding author: laurent.arbaret@univ-orleans.fr 


\begin{abstract}
The magnetite fabrics measured by anisotropy of magnetic susceptibility (AMS) and by Shape Preferred Orientation (SPO) optical methods are classically used as flow kinematics indicators in lava flows. The development of magnetite fabrics during simple shear strains $\gamma \leq$ 20 was performed using a suspension of $1 \%$ volume fraction of multidomain magnetite randomly contained in a mixture of silicone and wax. We measured AMS fabric and SPO ellipsoids by calculating a quadratic shape tensor from oriented thin-sections. For $\gamma<8$, fabrics obey to the theoretical model of rotation of Jeffery (1922). Fabrics are usable to determine the flow kinematics, including the amount of applied finite strain. For $\gamma>8$, fabric elements, foliation and lineation, stabilised closely parallel to the flow plane and the shear direction, respectively. Two- and three-dimensional numerical simulations using measured aspect ratios of magnetite point out that the large scattering of aspect ratios and the initial orientation distribution of particles are together responsible for a wide-ranging loss of periodicity. The stable AMS and SPO fabrics observed at large strains in experiments are the result of these primary fabric properties combined to collisions between particles and, possibly, their complex three-dimensional shapes. In addition, the constant angular relationship observed at large strains between fabrics and flow components is related to the transient collisions.
\end{abstract}

Consequently, the determination of the lava flow kinematics by using fabrics properties measured either by AMS or by SPO analyses should be indubitably associated to a detailed study of the three-dimensional shape of the solid carriers. Regularly shaped populations of low elongated particles will be capable to produce cyclic to oscillating fabrics, while the fabric of elongated particles will be more sensitive to the shape parameters and collisions, ultimately favouring stable fabrics at large strains.

Key words: 3D shape fabrics, AMS, simple shear, particle clustering, analogue modelling, numerical simulation. 


\section{Introduction}

Magmas flowing from their source are usually regarded as suspensions of crystals that behave as active (rigid) markers crystallising and rotating in a matrix (the melt) submitted to deformation. From decades, both Shape Preferred Orientation (SPO) and Anisotropy of Magnetic Susceptibility (AMS) of crystals populations are fabrics components widely used as flow direction and deformation regimes indicators (Cañón-Tapia, 2005; Borradaile and Jackson, 2010 for recent reviews). AMS is used in the case of paramagnetic and ferrimagnetic crystals such as biotite and multidomain magnetite respectively, for which the magnetic ellipsoid closely corresponds to the shape of the crystal (Borradaile, 1988; Rochette et al., 1992; Tarling and Hrouda, 1993; Borradaile and Henry, 1997; Hrouda and Ježek, 1999; Borradaile and Jackson, 2010). Two-dimensional image analysis on rocks-sections gives direct quantification of the SPO fabric ellipse (Launeau et al., 1990), while tensorial reconstruction applied to any three perpendiculars sections yield the SPO ellipsoid (Owens, 1984; Launeau and Cruden, 1998; Launeau and Robin, 2005). Many studies have applied, sometimes combining, these two approaches to determine the flow dynamics during magma emplacement in dikes (Philpotts and Asher, 1994; Tauxe et al., 1998; Callot et al., 2001, Geoffroy et al., 2002; Aubourg et al., 2002; Féménias et al., 2004; Poland et al., 2004; Bascou et al., 2005, Philpotts and Philpotts, 2007; Aubourg et al., 2008, Hastie et al., 2011), lavas flows (Cañón-Tapia et al., 1995; Cañón-Tapia, 2005; Loock et al., 2008) and domes (Arbaret et al., 1993; Cañón-Tapia and Castro, 2004; Závada et al., 2009). When identical, AMS and SPO fabrics properties are linked to magma flow dynamics by applying the theory of the motion and rotation of the crystals in the sheared medium (Dragoni et al., 1997).

The theoretical evolution of the SPO of rigid markers with progressive strain is based on the Jeffery's equations (1922) giving the cyclic motion of a uniaxial particle in a matrix submitted to deformation. Analytical solutions of these equations have been determined for different flow geometry such as simple shear (Jeffery, 1922), pure shear (Gay, 1968, Reed and Tryggvason, 1974) and axial flattening (Debat et al., 1975, Ježek et al., 1996; Freeman, 1985 
for general systems). The model considers that; i) the matrix has a Newtonian behaviour as recorded for silicate melts in the natural shear strain rates range (Petford, 2003), ii) the particle populations exhibit random initial orientations, homogeneous aspect ratios and, finally, iii) never interact. Moreover, the influence of newly appearing and growing crystals during cooling is not taken into consideration (Launeau and Cruden, 1998). Among these simplifications, shape distribution and mechanical (for SPO) and magnetic (for AMS) interactions between particles have been recognised for a long time as critical parameters favouring fabric deviation from theory (Blumenfeld and Bouchez, 1988; Tikoff and Teyssier, 1994; Grégoire et al., 1995; Arbaret et al., 1996; Gaillot et al., 2006).

The influence of the grain shape distribution on SPO development at large simple shear strains $\gamma$ remains poorly quantified. The numerical 2D simulations of Ildefonse et al. (1997) has evidenced a departure from a homogeneous population for normal log and Gaussian distributions having variances higher than 0.3. In particular, for $\gamma>10$, the SPO lineation stabilise parallel to the flow direction. A similar result is produced if new grains are added by continuous crystallisation in a melt during deformation (Launeau and Cruden, 1998).

In addition, contact-interactions and distribution anisotropy of magnetite grains have been extensively invoked as two factors that could potentially change the SPO, and more particularly, AMS fabric properties (Hargraves et al., 1991; Grégoire et al., 1995; CañónTapia, 2001; Gaillot et al., 2006). Borradaile and Puumala (1989) point out experimentally the good link between AMS fabrics of low concentration suspensions of magnetite and flow kinematics during moderate pure shear deformation (25\% shortening). Similar conclusions were proposed by Cogné and Canot-Laurent (1992) for hematite suspensions submitted to simple shear $\gamma \leq 1.4$. Recent works concluded that magnetic interactions, contact interactions through clustering, and intrinsic shape all play a role on AMS and SPO magnetite fabrics acquisition (Borradaile and Puumala, 1989; Hargraves,et al., 1991; Grégoire et al., 1995; Grégoire et al., 1998; Cañón-Tapia and Pinkerton, 2000; Cañón-Tapia, 2001; Gaillot et al., 2006). When particles are nearly isotropic in shape the AMS tensor is controlled by the distributions of grains (Hargraves,et al., 1991). Grégoire et al. (1998) and Cañón-Tapia (2005) 
concluded that the AMS fabric remains mainly controlled by the shape of magnetite when their average aspect ratio is larger than 1.6. This conclusion has been also reached by Gaillot et al. (2006) from analytical models and experiments on magnetic interactions. So far, however, the link between both AMS and SPO fabrics and flow dynamics remains debated in particular for large finite strains that are often recorded in lava flows and dykes.

In this contribution we study the behaviour of low concentrations (1\% volume) of magnetite particles undergoing large simple shear deformations $(\gamma \leq 20)$. Although many different deformation regimes are found in lava flows (Merle, 1998; Loock et al., 2008) and domes (e.g. Závada et al., 2009), we will focus on the simple shear deformation as it corresponds to the most common deformation regime encountered along conduit margins and bases of lavas flows where large finite strains are achieved (Merle, 1998). In addition, the simple shear is used as case study in many analogue (Fernandez et al., 1993; Ildefonse et al., 1992); numerical (Ježek et al., 1996) and experimental previous works (Borradaile and Puumala, 1989; Cañón-Tapia and Pinkerton, 2000). Since the link between AMS and SPO of a magnetite-alone suspension may be a function of intrinsic susceptibility (Archanjo et al., 1995) or shape geometry (Hrouda, 1982; Borradaile, 1991; Tarling and Hrouda, 1993; Borradaile and Henry, 1997; Grégoire et al., 1998; Cañón-Tapia and Castro, 2004), we combined AMS measurements with image analysis of SPO on oriented thin-sections. A threedimensional SPO ellipsoid was calculated using the quadratic shape tensor of Shimamoto and Ikeda (1976) by combining three mean grain inertia tensors measured on three perpendicular sections (Owens, 1984; Launeau and Cruden, 1998). Two- and three-dimensional numerical simulations are used to investigate the influence of both aspect ratio distribution and contact interactions on SPO and AMS fabrics development. A third numerical simulation is developed in order to estimate the probability of collisions of particles during shearing. Relationships between SPO and AMS fabrics and consequences of shape distribution and contact interactions on the use of fabrics as flow kinematics indicators at large strain regimes $(\gamma \leq 20)$ are discussed. 


\section{Apparatus and starting material}

\subsection{Apparatus}

In order to ensure homogeneous, large simple shear strain $(\gamma>4)$ within the magnetite suspension, we used a ring-shear apparatus composed of two concentric cylinders, which rotate with the same angular velocity but in opposite directions (Passchier and Sokoutis, 1993; Arbaret et al., 1997, Arbaret et al, 2001; Mancktelow et al., 2002; technical description of the apparatus in Arbaret et al., 1996). The fixed bottom of the ring shear rig is covered with a $2 \mathrm{~mm}$ thick layer of low-viscosity mineral oil acting as a lubricant. The fixed external reference frame used for measurements is defined with $\mathrm{XY}$ the surface of the undisturbed shear flow parallel to the surfaces of the cylinders and $X$ the direction of the shear (Fig. 1a).

In the ring shear apparatus the simple shear strain is not constant but depends on the radial distance $r$ between the centre of the sampling area and the rotation axis of the ring (Reiner, 1960). The shear strain rate $\dot{\gamma}$ applied at the sample position can be calculated with the equation proposed by Masuda et al. (1995) and experimentally confirmed by Arbaret et al. (2001) in a Newtonian matrix:

$$
\dot{\gamma}=\frac{-2\left(\dot{\Omega}_{i}-\dot{\Omega}_{e}\right)}{\frac{1}{R_{i}^{2}}-\frac{1}{R_{e}^{2}}} \frac{1}{r^{2}},
$$

where $R_{e}$ and $R_{i}$ are the radii and $\dot{\Omega}_{e}$ and $\dot{\Omega}_{i}$ the angular velocities of the external and internal boundaries respectively. In the ring shear used for these experiments, $R_{e}$ is $149.5 \mathrm{~mm}$ and $R_{i}$ is $96.0 \mathrm{~mm}$. The strain gradient affecting the sampling zone centered between the two cylinders was calculated by measuring the displacement rate of solid markers disposed at the surface of the material. We found a strain ranging from $\gamma=18.5$ to $\gamma=21.7$ for a maximum mean finite strain $\gamma=20$.

\subsection{Starting material}


The apparatus was filled with a suspension of $1 \%$ volume fraction of magnetite grains (Fig. 2). The magnetite grains were extracted from the basalt of the Tiretaine lava flow (Chaîne des Puys, French Massif Central, Loock et al., 2008). We selected the largest sieved crystal fraction ranging from 50 to $100 \mu \mathrm{m}$. Microprobe analysis of 50 grains showed that the compositions are ulvospinel-magnetite solid solution with the following average composition : $\mathrm{Mg}_{0.2} \mathrm{Fe}^{\mathrm{II}}{ }_{1.3} \mathrm{Al}_{0.2} \mathrm{Fe}^{\mathrm{III}}{ }_{0.3} \mathrm{Ti}_{0.5} \mathrm{O}_{3}$ calculated on 3 cations. This result is consistent with Curie temperatures at $90^{\circ} \mathrm{C}$ and $120^{\circ} \mathrm{C}$ found by Look et al. (2008). The particle size, the chemistry and the Curie temperatures indicate that the main susceptibility carrier for these experiments is multi domain titanomagnetite. Such mineral is known to have a normal magnetic fabric with an AMS dominated by the shape of the crystal. The $1 \%$ concentration of magnetite was chosen i) to insure that the apparatus used for AMS measurements as described below is not saturated and, ii) the particles are statistically far enough from each other in the starting product to reduce the magnetic interactions between neighbouring magnetite that can change the principal axes of the AMS ellipsoid (Hargraves et al., 1991; Grégoire et al., 1995; Grégoire et al., 1998). Furthermore, although magmas emplaced near, or at the surface, usually contain oxide up to 5\% volume fraction (Hargraves et al., 1991), the chosen volume fraction used for our experiments is comparable to magnetite concentrations found in many plutonic rocks and volcanic rocks such as picrite basaltic magmas (Hastie et al., 2011). No other differently shaped and larger solid phase was added to the suspension as it could have induced both mixed contributions in AMS fabrics (Borradaile and Gauthier, 2003; Borradaile and Jackson, 2010) and complex SPO fabrics by the formation of large stable clusters by translation of the grains in the sheared media (Ildefonse et al., 1992; Arbaret et al., 1996; Launeau and Cruden, 1998). These conditions, that constitute a fundamental approach to explore the AMS and SPO fabrics evolution at the late magmatic stage of emplacement, are not the scope of this contribution. Because of their small size and their natural low shape anisotropy, the perpendicular long axis $a$, intermediate axis $b$ and short axis $c$, that characterise the three-dimensional shape of each magnetite grain, cannot be determinated with precision. In addition, although numerical simulations exist for triaxial rigid markers (Jezek et 
al., 1994; Hrouda and Ježek 1999), we use the most common theoretical and numerical models that are based on axisymmetric particles (Jeffery, 1922; Reed and Tryggvason, 1974; Willis, 1977). The aspect ratio $\square \zeta=a / c$ of the particles was measured in 30 randomly oriented sections of the frozen starting material. The magnetite grain population exhibits a non homogeneous distribution of the aspect ratios with an average of $\bar{\zeta}=1.71 \pm 0.59$ (5069 grains analysed, Figure 3a). Arbaret et al. (2001) demonstrated that the rotational behaviour of a non-axisymmetric and parallelepipedic particle can be adequately described by the analytical solutions of Jeffery's equations if one of the axial ratios is less than about 1.5. Therefore, the description of our magnetite as uniaxial ellipsoids is considered to be a good approximation.

The matrix was composed of a mixture of a boropolysiloxane (main component of silicone putty "Silbione 70009" manufactured by Rhône Poulenc, 56\% volume fraction) and modelling clay (mixture of wax and unknown vegetal components, $44 \%$ volume fraction). The matrix closely approximates a Newtonian behaviour at the experimental temperature of $55^{\circ} \mathrm{C}$ and low constant shear rates (viscosity of $4.6 \times 10^{4}$ Pa.s at $20^{\circ} \mathrm{C}$ decreasing toward 5.6x $10^{3}$ Pa.s at $55^{\circ} \mathrm{C}$; Arbaret et al., 1997). It was solid at the sampling temperature of $-18^{\circ}$ C. To avoid any post-experiment deformations during the analytical procedures, cores for AMS measurement were placed in diamagnetic cylindrical PEHD holders and samples for SPO analysis were enclosed by paraffin. All fabric measurements were performed at a room temperature of $20^{\circ} \mathrm{C}$. Since magnetite has a mean susceptibility of $13.7 \mathrm{SI}$, the diamagnetic contribution $\left(-7.5 \pm 0.7 \times 10^{-5} \mathrm{SI}\right)$ of the matrix can be neglected.

\section{Fabric measurements}

\subsection{Low field magnetic measurements (AMS)}

AMS ellipsoids were measured on six samples, having a volume of $5.53 \mathrm{~cm}^{3}$, core-drilled at the end of each experiment (Fig. 1b). If we consider a constant grain diameter of $75 \mu \mathrm{m}$ that correspond to the median diameter of the sieved fraction, $1 \%$ volume solid fraction in a 
sample represent statistically more than $2.5 \times 10^{5}$ magnetite grains. Measurements were performed with a Kappabridge KLY2 apparatus (GeofyzikaBrno), working at $\pm 3.8 \times 10^{-4}$ Tesla and $920 \mathrm{~Hz}$. The AMS ellipsoid is defined by the principal susceptibility axes $k_{\max }>k_{\text {int }}>k_{\min }\left(\right.$ mean susceptibility $\left.k_{\text {mean }}=\left(k_{\max }+k_{\text {int }}+k_{\min }\right) / 3\right) .\left[k_{\max }, k_{\text {int }}\right]$ defines the magnetic foliation and $k_{\max }$ the magnetic lineation. For each sample $i(1 \leq i \leq 6)$, the symmetry $T_{i}$ which varies from -1 (prolate ellipsoid) to 1 (oblate ellipsoid) and the eccentricity $P_{i}$, are the Jelinek (1981) parameters defined as (Borradaile and Werner, 1994):

$$
T_{i}=\frac{\ln \left(k_{\text {int }} / k_{\text {min }}\right)-\ln \left(k_{\text {max }} / k_{\text {int }}\right)}{\ln \left(k_{\text {int }} / k_{\text {min }}\right)+\ln \left(k_{\text {max }} / k_{\text {int }}\right)} \text { and }
$$

$P_{i}=\exp \sqrt{2\left[\left(\ln k_{\max } / k_{\text {mean }}\right)^{2}+\left(\ln k_{\text {int }} / k_{\text {mean }}\right)^{2}+\left(\ln k_{\min } / k_{\text {mean }}\right)^{2}\right]}$.

For each experiment, the principal axes $K_{\max }, K_{\text {int }}$ and $K_{\min }$ of the mean magnetic ellipsoid were calculated by averaging the magnetic ellipsoid of each samples ensuring weighting by the degree of anisotropy (Ernst and Pearce, 1989). $T$ and $P$ were calculated from this average ellipsoid and should not be confused with an arithmetic average of $T_{i}$ and $P_{i}$ calculated for each sample.

\subsection{Image analysis $(S P O)$}

The image analysis was applied to three perpendicular sections cut parallel to the principal planes of the finite strain ellipsoid (Fig. 1c). On each image, representing about $4 \mathrm{~cm}^{2}$, an average of $220 \pm 30$ magnetite grains have been analysed. The aspect ratio of a grain $j$ is defined as $\zeta_{j}=\sqrt{\lambda_{j 1} / \lambda_{j 2}}$ where $\lambda_{j 1}, \lambda_{j 2}$ are the eigenvalues of the inertia shape tensor $\mathrm{M} j$ given by (Launeau and Cruden, 1998):

$$
\mathbf{M}_{j}=\left|\begin{array}{l}
m_{x x} m_{x y} \\
m_{x y} \\
m_{y y}
\end{array}\right|
$$

where $m_{x x}=\frac{1}{A} \sum_{i}\left(x_{i}-x_{c}\right)^{2}, m_{x y}=\frac{1}{A} \sum_{i}\left(x_{i}-x_{c}\right)\left(y_{i}-y_{c}\right)$ and $m_{y y}=\frac{1}{A} \sum_{i}\left(y_{i}-y_{c}\right)^{2}$ with $x_{i}$ and $y_{i}$ the pixel coordinates of the grain and $x_{c}=\bar{x}_{i}$ and $y_{c}=\bar{y}_{i}$, the coordinates of the centroid of 
the grain $j$ of surface area $A$. The long axis orientation $\alpha_{j}$ of the grain is given by the greatest eigenvector of $\mathrm{M}_{j}$.

The two-dimensional shape preferred orientation of the grain population is calculated by averaging the inertia tensor of each grain, which gives an ellipse weighted by the area of the grains as follow (Launeau and Cruden, 1998):

$$
\mathrm{M}=\frac{1}{N} \sum_{j} \mathrm{M}_{j}=\frac{1}{N}|| \begin{gathered}
\sum_{j} m_{x x j} \sum_{j} m_{x y j} \\
\sum_{j} m_{x y j} \sum_{j} m_{y y j} \mid
\end{gathered} \mid
$$

The aspect ratio of the grains population, $\zeta=\sqrt{\lambda_{1} / \lambda_{2}}$ and their orientation $\alpha$ are given by the eigenvalues and maximum eigenvector of $\mathrm{M}$ respectively.

As established by Shimamoto and Ikeda (1976), three mutually 2D quadratic shape tensors can be combined to calculate one 3D quadratic shape tensor. The 2D quadratic shape tensors can be obtained from inertia tensors calculated on each section, and the corresponding ellipsoid can be calculated by the averaging method (Launeau and Cruden, 1998; Robin, 2002). It should be noticed that the resulting 3D tensor calculated in this form include some noise from the fact that three different grain populations were combined together on its calculation. We will refer to this ellipsoid as the SPO ellipsoid. The main ellipsoid axes are $S_{\max }, S_{\text {int }}$ and $S_{\min }$ with $\left[S_{\max }, S_{\text {int }}\right]$ defining the SPO foliation with $S_{\max }$ the SPO lineation. The orientation of the ellipsoid axes, the symmetry $\left(T_{s}\right)$ and the eccentricity $\left(P_{s}\right)$ of this SPO ellipsoid can be therefore compared to those obtained for the AMS ellipsoid.

\section{Evolution of fabrics versus shear strain}

Eight experiments were performed to reach different shear strains, namely $\gamma=1,2,3,4,8,12$, 16 and 20. Six cores for AMS measurements and three perpendicular sections for SPO measurements were sampled on each experiment. AMS and image analysis results are presented in Fig. 4. Orientations of the main axes of both AMS and SPO ellipsoids are plotted in equal area stereonets and corresponding symmetry coefficients $T$ are plotted versus eccentricity coefficients $P$. 
At $\gamma=1$, the shape parameters of the AMS samples ellipsoids show a scattered distribution with $T$ ranging from -0.7 to 0.7 and $P$ ranging from 1.15 to 1.3 (Fig. 4 ). The SPO and AMS mean ellipsoids are characterised respectively by $\left[S_{\max }, S_{\text {int }}\right]$ and $\left[K_{\max }, K_{\text {int }}\right]$ planes closely parallel to the bottom surface of the ring shear (i.e. closely parallel to the $\mathrm{XZ}$ plane). These fabrics properties are possibly due to the manual emplacement of the analogue material in the apparatus as already inferred in previous experiments where similar primary fabrics have been recorded at $\gamma=0$ stages (Arbaret et al., 1997).

At $\gamma=2$, the distribution of the directions $k_{\max }, k_{i n t}$ and $k_{\min }$ of the AMS samples become less scattered than for $\gamma=1$. The average magnetic lineation $K_{\max }$ is well defined, while $K_{\min }$ - and more particularly $K_{\text {int }}$ - remains less defined, as illustrated by the spread distribution of the AMS samples symmetry $T_{i}$. In terms of direction of principal axes, the SPO ellipsoid shows a close correspondence with the AMS ellipsoid. However the shape parameters of both ellipsoids are significantly different as the SPO ellipsoid is strongly oblate with a low eccentricity while the AMS ellipsoid is characterised by a moderate eccentricity and a prolate shape. Measurements point to the acquisition of new shape and magnetic fabrics showing comparable main directions. The development of these new fabrics, homogeneously distributed over the deformed suspension, is attributed to the controlled deformation applied during the experiment.

For $3<\gamma<20, k_{\max }$ directions of AMS samples ellipsoids progressively concentrate and tend to stabilise, making an angle of 10 to $15^{\circ}$ with the direction of shear $\mathrm{X}$, except for $\gamma=8$ during which these two directions are almost parallel (Fig. 4). For the measured strain stages, the main direction $S_{\max }$ of the SPO ellipsoid is nearly similar to mean direction $K_{\max }$. The AMS foliation plane $\left[K_{\max }, K_{\text {int }}\right]$ is always close to the plane of the undisturbed flow while $\left[S_{\max }, S_{\text {int }}\right]$ is parallel to $\left[K_{\max }, K_{\text {int }}\right]$ for $\gamma=4,8$ and 20 , or nearly perpendicular for $\gamma=12$ and 16. This discrepancy between SPO and AMS foliations at $\gamma=12$ and 16 are due to the close eigenvalues of the intermediate $S_{\text {int }}$ and minors axes $S_{\min }$ that generate inversion between the two axes. This close correspondence between the intermediate and minor eigenvalues of both ellipsoids is also illustrated by their symmetry $T$ and $T_{S}$ that are always in the prolate domain 
with a minimum for $T=-0.7$ at $\gamma=16$ and $T=-0.8$ at $\gamma=12$. In the same way, symmetry parameters $T_{i}$ of AMS samples progressively concentrate and for $\gamma>12$, all samples exhibit a prolate shape. Both eccentricities $P$ and $P_{S}$ show a similar evolution from about 1.27 at $\gamma=3$ to less than 1.1 for $\gamma>16$.

From these series of experiments, the evolution of the mean AMS and SPO fabrics with increasing shear deformation can be divided in two successive stages: The first stage, for $0<$ $\gamma<4$, is characterised by the development of new shape and magnetic fabrics, already acquired at $\gamma=2$, that show a progressive rotation of foliation and lineation toward the plane of undisturbed flow and direction of shear respectively. The second stage, that includes shear strains larger than $\gamma=4$, is characterised by direction and shape properties of both magnetic and SPO fabrics that tend to stabilise.

\section{Numerical simulations}

Three series of numerical simulations have been performed. The first series comprises of three-dimensional simulations using the aspect ratios measured on the magnetite grains. The second series of simulations are based on ten two-dimensional calculations using the aspect ratios of the magnetite grains but for each different random initial orientations are applied. Finally, a third simulation is performed in order to estimated the percentage of collisions of grains appearing at a given instant during deformation.

\subsection{Three-dimensional SPO simulations}

The three-dimensional path of an axisymmetric particle in a Newtonian linear-viscous matrix undergoing homogeneous simple shear is given by the analytical solutions of the Jeffery's equations (Jeffery, 1922; Reed and Tryggvason, 1974; Willis, 1977):

$$
\begin{aligned}
& \tan \varphi^{\prime}=\zeta \tan \left[\frac{\zeta \gamma}{\zeta^{2}+1}+\arctan \left(\frac{\tan \varphi}{\zeta}\right)\right] ; \\
& \tan ^{2} \theta^{\prime}=\tan ^{2} \theta\left[\frac{\zeta^{2} \cos ^{2} \phi+\sin ^{2} \phi}{\zeta^{2} \cos ^{2} \theta^{\prime}+\sin ^{2} \phi^{\prime}}\right] ;
\end{aligned}
$$


$\zeta$ is the aspect ratio a/c of the particle. The angles $\left(\phi, \phi^{\prime}\right)$ and $\left(\theta, \theta^{\prime}\right)$ represent the azimuth and plunge of the long axis a relative to the plane of undisturbed flow measured before and after the incremental shear strain $\gamma$. Eqs. (6) and (7) imply that the motion of an axisymmetric particle is cyclic, with a semi period $\gamma_{c}$ depending on its aspect ratio as follow (Fernandez et al., 1983):

$$
\gamma_{c}=\frac{2 \pi}{\sqrt{1-\Gamma^{2}}}
$$

where $\Gamma$ is the shape factor given by (equivalent to the factor $\mathrm{K}$ of Willis, 1977):

$$
\Gamma=\frac{\zeta^{2}-1}{\zeta^{2}+1} .
$$

The instantaneous angular velocity is always at a minimum when the long axis of the particle is parallel to the shear direction X. End-members are, on one side, spherical particles that display a constant angular velocity and, on an other side, particles with an infinite aspect ratio for which the long axis a rotates asymptotically toward the shear axis with strain.

As already noted, the three-dimensional shape properties of each magnetite particles is not precisely known. Therefore, for the three-dimensional simulation we used a simplified population composed of 8 normal log distributed sub-populations of identically shaped axisymmetric particles (Fig. 3a). The average aspect ratio of the whole population is $\zeta=1.71$.

For all calculations, the particles were randomly oriented at the initial stage $(\gamma=0)$. Equations (6) and (7) were applied to each particle with a shear step of 0.125 for $0<\gamma<2$ and 0.5 for $\gamma>2$. The shear strains steps are $0.5 \gamma$. Particular steps that correspond to the finite strains reached in analogue experiments, namely $\gamma=1,2,3,4,8,12,16$ and 20, are showed in fig. 5 and 6. For each stage, the orientation of the ellipsoid axes $S_{\max }, S_{\text {int }}$ and $S_{\min }$, the symmetry $\left(T_{s}\right)$ and the eccentricity $\left(P_{s}\right)$ of the inertia shape tensor representing the SPO ellipsoid of the whole population were calculated using the tensorial method already described for image analysis (Launeau and Cruden, 1998).

For the first simulation, we considered a population of 800 axisymmetric particles having an homogeneous aspect ratio $\zeta=1.71\left(\gamma_{c}=7.21\right)$ that correspond to the average aspect ratio of the magnetite grain population. At $\gamma=0$, the SPO fabric was characterised by a SPO lineation 
$S_{\max }$, close to the $\mathrm{Z}$ direction, i.e. perpendicular to the direction of shear, with a large standard deviation of $\sigma_{\max }= \pm 34.4^{\circ}$ (Fig. 5). The eccentricity of this initial fabric was significantly low with $P_{s}=1.04$ and a symmetry $T_{s}=0.65$. For $0<\gamma<4, S_{\max }$ progressively rotated with a decreasing of $\sigma_{\max }$ from $34.4^{\circ}$ to $20.0^{\circ}$. At $\gamma=4$, that correspond to the closest stage to the first theoretical semi period $\left(\gamma_{c} / 2=3.61\right), S_{\max }$ and the SPO foliation $\left[S_{\max }, S_{\text {int }}\right]$ were closely parallel to the shear direction and the plane of undisturbed flow respectively as expected by the theory. For highest strains, the orientation of the fabric evolve according to the theory. The strongest shape fabrics is found with $T_{s}=0.02$ and $P_{s}=1.88$ when the mean fabric orientation is parallel to the direction of shear.

In the second three-dimensional simulation, we considered a population of 800 particles whose distribution and average aspect ratio best represent the magnetite population (fig. 3a; normal $\log$ distribution; Marsh, 1988). The random initial orientation of the particles population formed a shape fabric with an orientation close to those obtained for the first simulation (Fig. 6). For $0<\gamma<4$, the foliation $\left[S_{\max }, S_{\text {int }}\right]$ progressively rotated to became nearly parallel to the plane of undisturbed flow $[\mathrm{X}, \mathrm{Z}]$ at about $\gamma=4$, with $\mathrm{S}_{\max }$ close to the direction of shear X. This is similar to the evolution already noted in the previous simulation for the homogeneous population(Fig. 7a). The standard deviation of the SPO lineation $S_{\max }$ started at $\sigma_{\max }= \pm 34.4^{\circ}$ to decrease regularly to $\sigma_{\max }= \pm 25.9$ at $\gamma=4$. During this stage, eccentricity $T_{s}$ was low, between -0.10 and -0.20 , excepted for the initial stage of the shape fabric where $T_{s}$ was 0.64 . The associated symmetry $P_{s}$ increased progressively up to 1.66 but never reached the maximum value obtained at $\gamma=4$ by the homogeneous population (Fig. $7 \mathrm{~b}$ ). For $4>\gamma>20,\left[S_{\max }, S_{\text {int }}\right]$ oscillated around $[\mathrm{X}, \mathrm{Z}]$ with a maximum angle of $22^{\circ}$ (Fig 7a). $S_{\max }$ was always close to the direction of shear with a corresponding standard deviation varying from $\sigma_{\max }= \pm 27.8^{\circ}$ to $\sigma_{\max }= \pm 32.5^{\circ}$ (Fig. 6). The eccentricity $T_{s}$ oscillate between -0.10 and -0.62 and the symmetry $P_{s}$ showed larger oscillations between 1.13 and 1.66 with an average of $1.56 \pm 0.28$ for $\gamma>6$ (Fig. $7 b$ ).

These results indicates that, the SPO foliation $\left[S_{\max }, S_{\text {int }}\right]$ and lineation $S_{\max }$ were similar for both homogenous and normal $\log$ distributed populations for $\gamma<4$. However, a significant difference comes from the evolution of the symmetry $\left(T_{s}\right)$ and the eccentricity $\left(P_{s}\right)$ of the normal log distributed population that deviate from the first simulation already at shear strains 
as low as 1.5. For $\gamma>4$, all fabric components of the normal $\log$ distributed population irregularly oscillate with a progressive drop in amplitude with increasing strain..

\subsection{Two-dimensional SPO simulations}

The two-dimensional analytical solutions describing the rotation path of a particle located in the plane perpendicular to the rotation axis can be derived from equations (6) and (7) as (Gay, 1968; Fernandez et al., 1983):

$$
\arctan \left(\zeta \tan \alpha^{\prime}\right)=\arctan (\zeta \tan \alpha)-\frac{\gamma}{2} \sqrt{1-\Gamma}
$$

where $\alpha$ and $\alpha^{\prime}$ are the orientation of the long axis $a$ of the particle before and after the incremental shear strain $\gamma$ and $\Gamma$ as previously defined in equation (9).

Because of the non-homogeneously distributed population of the aspect ratios, the evolution of the shape fabric versus strain depends on the initial orientation attributed to each particle. Ten numerical simulations were successively performed using different random initial distributions of orientations for particles having aspect ratios measured on the magnetite grains (800 grains; Fig. 3b). For each simulation and simple shear step of 0.1 , equation (10) was applied to each particle and a quadratic shape tensor representing the two-dimensional fabric ellipse was calculated (Shimamoto and Ikeda, 1976). The resulting evolution versus strain of the simulated orientation $\alpha$ and simulated intensity $I$ of this average fabric ellipse are presented in fig. 8. This simulation is compared with the evolution of a theoretical population of ellipses all having the average aspect ratio $\zeta=1.71$ of the magnetite population with an homogeneously distributed initial orientation. Finally, the three-dimensional analogue results (AMS and SPO) are compared to these simulations by using XZ sections of there respective tensors. 
For $\gamma=0$, shape fabrics were already present as they were controlled by the initial orientation of particles in each simulation. The orientations $\alpha$ varied from $-37.3^{\circ}$ to $43.7^{\circ}$ and the intensities I varied from 1.02 to 1.12 (Fig.8). For $1<\gamma<4$, $\square$ all orientations $\alpha$ became very close to those obtained for the theoretical population while intensities I remained scattered. For $\gamma>4$, different shape fabric evolutions were observed. The populations having an initial shape fabric property close to those expect from the theory $\left(\alpha= \pm 45^{\circ}\right.$ and $\left.\mathrm{I}=1.00\right)$ evolved according to the theory up to $\gamma \sim 12$ (one simulation numbered 1 in Fig. 8). On the contrary, some simulations were caracterised by a tendancy to stabilisation of $\alpha$ close to the direction of shear with irregular intensities I (two simulations numbered 2 in Fig. 8). Intermediate behaviours were commonly reproduced (examples numbered 3 in Fig. 8). They were characterised by irregularly oscillating fabrics with backward rotation of the orientations with respect to the applied sense of shear; in particular close to the theoretical semi periods. This 2D calculation shows that the fabrics evolution in a simple shear flow of a population of particles having non-homogeneous aspect ratios is strongly dependant to their initial orientation. The theoretical cyclicity of the shape fabric components could be partly conserved even at very large strains while in other cases the stability is reach since $\gamma \sim 4$. However, the most common case remains represented by irregularly oscillating fabrics caracterised by a decreasing amplitude in both orientation and intensity with increasing strain $\gamma$

SPO and AMS fabrics calculated in XZ sections of there respective 3D tensors yielded orientations and intensities comparable to both the theory and general tendency formed by the ten simulations for $\gamma<8$. For larger strains, the orientions were always found at about $15^{\circ}$ over the shear direction. The intensitisies I became lowers than 1.1 for $\gamma>12$. These values were different than those expected from the theoretical model for the explored finite strains. This is particular visible for $\gamma=12$ and $\gamma=20$ while for $\gamma=16$ SPO and AMS fabrics fit the theory (Fig. 8).

\section{3. grain collision simulation}


The number of collisions between grains at a given instant in a solid suspension undergoing simple shear deformation can be estimated by combining two parameters, which are the prediction of the collision rate (i.e. the number of collision appearing in the system per unit volume at a constant shear strain rate) and the estimation of the time span of collision (i.e. the time during which the two particles are in contact).

In low concentration suspensions, the collision rate $N c$ per unit volume $V$ of $N$ identical (the particles display the same shape properties), zero-inertia, particles in simple shear flow is (Sundaram and Collins, 1997; Hu and Mei, 1998, Collins and Sundaram, 1998):

$$
N_{c}=\frac{1}{2} \frac{N(N-1)}{V^{2}} \frac{V}{\left(V-8 V_{p}\right)} \Gamma \text {. }
$$

$V p$ is the volume of a particle and $\Gamma$, called collision Kernel, is written as (Wang et al., 1998):

$$
\Gamma=\frac{4}{3} \dot{\gamma} v^{3}
$$

where $v$ is the collision radius, which is the diameter of the particles for a monodisperse system. The solid suspension we used for calculation is composed of $1 \%$ volume fraction of homogeneously distributed spheroids of $75 \mu \mathrm{m}$ in diameter, which correspond to the median diameter of the sieved fraction of magnetite. The probability to obtain collisions of particles is a function of the number $N$ of particles, the statistical uncertainty to obtain collisions in the suspension decreasing with increasing amount of particles used for the numerical simulation. A calculation with increasing number of particles in our suspension showed that the collision rate increased with the number $N$ of particles and stabilised for $N>10^{4}$ (inset graph in fig. 9). Therefore, in order to avoid this statistical uncertainty at low amounts of particles, we used a population of $N=10^{5}$ particles. For this population, we obtained a collision rate $N c=$ $4.611 \times 10^{-1} \mathrm{~cm}^{-3} \cdot \mathrm{s}^{-1}$ at a constant strain rate $\dot{\gamma}=8.10^{-4} \mathrm{~s}^{-1}$ (equivalent to the strain rate applied in analogue experiments). The cumulated percentage of collided particles increased linearly with shear strain (Fig. 9). At $\gamma=4,10 \%$ of particles have collided, this percentage increasing to $50 \%$ at $\gamma=20$. 
The second parameter is the time span of collision. This parameter depend on the geometry of collision and on the aspect ratio of the particles and cannot be easily predicted (Arbaret et al., 1996, Mulchrone et al., 2005). However, a strain span of collision $\gamma_{s p}$ between two particles as a function of their aspect ratio $\xi$ can be estimated from the two-dimensional experiments on tiling development performed at a constant strain rate (Arbaret et al., 1996 and unpublished data, fig. 10). Results show that, in the range of commonly observed aspect ratio in rocks $(1<$ $\xi<3$, fig. 10), the strain span of collision $\gamma_{s p}$ increase linearly with the aspect ratio of the particles, starting at slightly higher than 2 for $\xi=1$. This value was chosen as a minimum and computed with the collision rate previously calculated for your theoretical population of spherical particles. We obtained a minimum of $5 \%$ of particles colliding at a given instant in our magnetite suspension.

\section{Discussion}

Ours experiments performed with analogue magnetite suspensions have been combined with three sets of numerical simulations. This approach allows to precise the respective influence of the non homogeneous distribution of aspect ratios of the particles, there initial orientations and contact-interactions (collisions) on the evolution of both AMS and SPO fabrics developed by magnetite bearing magmas deformed up to large simple shear strains ( $\gamma \leq 20$, Fig. 11). We now discuss the relationships between SPO and AMS fabrics and the flow at the light of theses results.

\subsection{Low shear regime $(\gamma<8)$}

The magnetic response of anisometric grains of multidomains magnetite in our low concentration (1\% volume fraction) suspension is expected to be shape controlled (Rochette et al., 1999; Cañón-Tapia, 2005). consequently, the AMS ellipsoid is theoretically in agreement with the SPO ellipsoid. For low shear strains $(\gamma<8)$, we evidenced that the directional and shape properties of SPO and AMS ellipsoids in experiments evolve according to the theoretical model of Jeffery (1922). Borradaile and Puumala (1989) already point out 
experimentally the good link between AMS and SPO fabrics of low concentrated magnetite and flow kinematics during moderate pure shear deformation (25\% shortening). Similar conclusions were also proposed by Cogné and Canot-Laurent (1992) for hematite suspension submitted to simple shear $\gamma \leq 1.4$. Consequently, our experiments confirm that the magnetite fabrics measured either by magnetic or optical approaches could be linked to the deformation kinematics, including the amount of applied finite strain, of controlled simple shear flows $\gamma<$ 8 by using the theoretical model of Jeffery (1922).

\subsection{High shear regime $(\gamma>8)$}

For high finite strains explored in the analogue experiments, AMS and SPO fabrics are characterised by an mean orientation $\alpha$ at about $15^{\circ}$ over the shear direction and an intensity of less than 1.1. The numerical simulations pointed out that, at such strains, the normal log distribution of aspect ratios of magnetite grains and their initial orientation generated irregularly oscillating fabrics whose amplitude decreased significantly with the progressive deformation. Nevertheless, particular fabrics were also observed. For instance, stable fabrics, in term of orientation closely parallel to the shear direction, were observed in $20 \%$ of the simulations (Fig. 8). On the contrary, a cyclic fabric closely following the theory were also reproduced. Cañón-Tapia and Chávez-Álvarez (2004) found also fabric orientations perpendicular to the flow direction suggesting the rare persistence of cyclic fabrics for low elongated particles. The general tendency of loss of periodicity with strain have been numerically modelled by Ildefonse et al. (1997) in 2D, and by Launeau (2004) and CañónTapia and Chávez-Álvarez (2004) in 3D for particles population with various mean aspect ratios, initial distributions and very high strains $(\gamma \leq 50)$. All these studies concluded that the fabric evolution is strongly dependant of the initial orientation and aspect ratio distributions of elongated particles. The third factor numerically estimated in the present study is the contactinteraction between particles that occurs during their relative motion in the flowing matrix. The contact-interactions of particles in our magnetite suspension is found to be around $5 \%$ of colliding particles at a given instant, which means that $50 \%$ of the magnetite has potentially suffered at least one collision at $\gamma=20$. As already evoked in the introduction, the contact 
interactions between particles is a critical factor for fabric stabilisation in solid suspensions containing over about $15 \%$ of particles. In lavas, the solid fraction during flow is often considered well below this fraction during the active flow (Cashmann et al., 1999; CañónTapia and Herrero-Bervera, 2009). For that reason the particle collisions are considered negligibles. Hence, stable fabrics are unlikely to develop, in particular for low elongated particles and even at large strains (Cañón-Tapia and Herrero-Bervera, 2009). Another factor can also affect the cyclic behaviour of particle embedded in a fluid submitted to a simple shear deformation. In the present study, the three-dimensional shape of minerals is not quantified. Particles with complex shapes are known to follow open paths instead of Jeffery's orbits (for instance triclinic shapes as observed by Arbaret et al., 2001). The concrete influence of such open paths on the fabric evolution at very large strains, and thus covering several theoretical rotation cycles, is still unknown. The magnetite grains we used for analogue modelling exhibit complex shapes since they come from crushed and sieved natural magnetites that were originally idiomorphic and, most likely, less elongated. Adding together the effect of the large distribution of shape ratios (Fig. 3a), the non homogeneously distributed initial orientation (Fig 5, $\gamma=0$ ), the perturbation in the rotational behaviour produced by the particles collisions and, possibly, open path trajectories due to the complex three-dimensional shapes, stable fabrics are likely to develop in very low solid suspensions submitted to large strains. This conclusion is supported by SPO and AMS results issued from our analogue modelling at $\gamma>8$.

Complexes, irregularly oscillating to stable, fabrics at large strain were also evidenced by numerous previous numerical and analogue works performed on solid anisometric particle populations embedded in a Newtonian medium submitted to a simple shear deformation (Fernandez et al., 1983; Ježek et al., 1994; Ježek et al., 1996; Arbaret et al. 2000; Yamato et al., 2011). Fabric stabilisation at large strains $\gamma \leq 20$ has been observed in analogue experiments using concentrations of biotite varying from 5\% to $45 \%$ volume (Arbaret et al., 1997). Stable orientations have been also modelled by Cañón-Tapia, E. and Chávez-Álvarez (2004) for $\gamma<10$ using particles with aspect ratios $\zeta>2$. They also showed that both the 
initial orientation distribution and the aspect ratios of particles take a role on the stabilisation of the mean fabric. Stable fabrics are also produced if new grains crystallise in the melt during progressive deformation and cooling (Launeau and Cruden, 1998), a process which cannot be reproduced in our experiments. For single particle systems, stabilisation with the long morphological axis of the particle closely parallel to the direction of flow have been observed with slipping particle/fluid interface (Arbaret et al., 2001; Mancktelow et al. 2002). Stable orientations in multi-particle systems with slidding interface were reproduced in analogue 2D experiments by Ildefonse and Mancktelow (1993). A similar behaviour have been obtained with a low viscosity layer as interface (Marques et al., 2005a). Particle stabilisation is also found in confined shear flows (Marques et al., 2005b). All these cases could produce resulting fabrics with stable orientation closely parallel to the direction of flow. In complex flows, Jezek et al. (1994) numerically created irregularly oscillating fabrics in simple shear that become stable when introducing a significant pure shear component.

\subsection{Origin of the angular relationship between fabrics and flow components}

For strains $\gamma>12$, we evidenced AMS and SPO foliations and lineations oriented preferentially at $10-15^{\circ}$ over the plane of undisturbed flow and direction of shear respectively (fig. 3, 8 and 11). These angular relationships are never reproduced in the numerical simulations as we observed fabrics that oscillate around the flow direction with an amplitude, depending on the initial distribution of the particles, and that decreased with strain. In previous studies performed with largest solid fractions composed of anisometric particles, a similar angular relationship between fabric and flow components at large strains obliquity has been noticed and attributed to the contact-interactions between particles (Ildefonse et al., 1992, Arbaret et al., 1996). A similar origin have been proposed in the numerically based study of Tikoff and Teyssier (1994) and modelled by Mulchrone et al. (2005). Direct contact interactions between particles develop during their relative motion in the shear flow direction. The collision between particles and there imbrication geometry is known from a long time in granular materials (Rees, 1968; 1979; see Mulchrone et al., 2005 for a recent review). The 
larger the strain, the higher the probability of interactions even for very low concentrations (as low as $1 \%$ solid volume fraction, Wang et al. 1998; Mulchrone et al., 2005). In two dimensions and low concentration suspensions submitted to simple shear, collision between two anisometric particles is described as a cyclic phenomenon ("tiling" system of Blanchard et al., 1979; Blumenfeld and Bouchez, 1988; Tikoff and Teyssier, 1994; Arbaret et al., 1996; Mulchrone et al., 2005). During collision, two particles can be considered as a single rotating particle having a monoclinic shape, which reaches a minimum angular velocity when the long axis of the two collided particles is $5^{\circ}$ to $15^{\circ}$ to the shear direction (Mulchrone et al., 2005). The value of this angle depends on the aspect ratio of the particles and the area of the contact (Arbaret et al., 1996; Mulchrone et al., 2005). Consequently, when enough collisions take place at a given instant, fabric elements lineation and foliation stabilise obliquely compared to the shear direction and plane respectively (Arbaret et al., 1996).

Tiling geometry made by two grains in contact or trends composed of many grains have been evidenced in natural magmatic flows (Blumenfeld and Bouchez, 1988; Tikoff and Teyssier, 1994). They are often observed along the margins of dikes and at the base of lavas flows and domes (Philpotts and Asher, 1994; Correa-Gomes et al., 2001); along which they are often used as a good statistical sense of shear indicators (Blumenfeld and Bouchez, 1988; Mulchrone et al., 2005). It is invoked among others hypotheses to explain the development of imbrications features marked by an angle between $\mathrm{K}_{\max }$ and the flow direction by Dragoni et al. (1997).

In $\left[S_{\max }, S_{\min }\right]$ sectional views of our experiments we evidenced only rare evidences of trends of two collided particles. This lake of observation could be due to stereological difficulties to statically cross-cut such trend of particles that, in addition, involve a relative low number of particles in our suspension. Despite this uncertainty, and on the basis of both experimental, numerical and field evidences cited above, we preferentially attribute the angular relationships between AMS and SPO fabric properties and flow components to the influence of transient contact-interactions between magnetite grains at $\gamma>8$. Nevertheless, complementary studies combining 3D particle clusters analysis and numerical simulations that take into account the 
particles collisions are needed to definitively conclude that the particle interactions have a significant role, or not, on the fabrics development in low solid suspensions submitted to very large strains, in particular by using magnetite grains with shapes more representative of natural, idiomorphic, crystals as encountered in lavas.

\section{4. application to magma flow determination in lavas}

The analogue approach we chosen is based on simplified experimental setup and materials, designed to control a limited number of parameters compared to the natural flowing magmas. It is coupled with numerical simulations that are also based on simplified models. However, keeping all the limitations in minds, our results allowed us to stress the mains parameters that influence the development of fabrics and how fabric can be used for reconstruct the flow emplacement history in lavas.

Our experiments evidence that directional properties of both SPO and AMS fabrics yield a direct comparison with the flow directions at large shear strains. This geometrical relationships correspond to the type I fabrics as defined by Aubourg et al (2002). These results confirm the fieldwork-based interpretations on the link between SPO and AMS fabric and flow kinematics obtained in both basaltic (Cañón-Tapia et al., 1995; Tauxe et al., 1998; Geoffrey et al, 2002; Cañón-Tapia, 2005, Hastie et al., 2011) and high-silica lava flows and dikes (Aubourg et al., 2002; Poland et al., 2004; Cañón-Tapia and Castro, 2004). These fabrics are regarded as the most commons structures in lava flows. Nevertheless, Cañón-Tapia and Chávez-Álvarez (2004) and Cañón-Tapia and Herrero-Bervera (2009) demonstrated through, respectively, theoretical and field approaches that oscillating, and even cyclic, fabrics are capable to persist within certain conditions in lava flows. Ours 2D simulations confirm their conclusions. In such conditions, the interpretation of fabrics properties measured either by AMS or by SPO should indubitably be associated to a detailed study of the shape properties of the solid carriers. In particular, the shape ratio distribution and the three-dimensional shape of the particles appear as major parameters which should be analysed with caution. Homogeneously shaped populations of low elongated particles will favour the 
persistence of cyclic fabrics, while, for elongated particles, the SPO development will be more sensitive to other shape parameters, ultimately favouring stable fabrics (Cañón-Tapia and Chávez-Álvarez, 2004).

Finally, because of there low intensity, such early magmatic shape fabrics developed under large simple shear deformation are very sensitive to changes in deformation history. A complex deformation history may either originates from a volume lose by melt extraction at the late magmatic stage (Bouillin et al., 1993), over-imposition of a tectonic related stress (Correa-Gomes et al., 2001), change of flow regime during early emplacement (Merle, 1998; Philpotts and Philpotts, 2007, Hastie et al., 2011) or during solidification in lavas (CañónTapia and Pinkerton, 2000).

\section{Conclusion}

We modelled magnetite SPO and AMS fabrics of a suspension composed by $1 \%$ volume fraction of multidomain magnetite. Our results confirm that AMS fabrics closely approximate SPO fabrics.

For low strains $\gamma<8$, the maximum axes rotated toward the shear flow direction while the fabric intensity increased with strain. Consequently, finite strain and flow geometry during early magmatic emplacement can be estimated from the directional properties and shape of AMS and SPO fabric ellipsoids using the Jeffery's model (1922).

For large strains $\gamma>8$, the fabric elements, foliation and lineation, stabilised closely parallel to the flow plane and direction, respectively. The fabric intensities remained stables at less than 1.1. Numerical simulations using measured aspect ratios of magnetite point out that the large scattering of aspect ratios and the initial orientation distribution of particles are together responsible for a wide-ranging loss of periodicity. The stable AMS and SPO fabrics reproduced in the analogue experiments are the result of these primary fabric properties combined to collisions between particles and, possibly, their complex tri-dimensional shapes. 
Consequently, the use of SPO and AMS fabrics as kinematics indicators for reconstruct the flow emplacement history in lavas at large strain regimes should be indubitably supported by a detailed study of the three-dimensional shape properties of the solid carriers. The accurate influence of contact-interaction of particles on the development of stable fabrics instead of the persistence of cyclic to oscillating fabrics in very low solid suspensions need further investigations. Ultimately, such magmatic shape fabrics developed in large simple shear flows present very low orientation intensities. As a result, they are very sensitive to any change in shear flow properties or subsequent late magmatic deformation, if present.

\section{Acknowledgments}

LA. and P.L. acknowledge support by the French Ministery of Education and Research (ACI JC3013, "Fabriques magmatiques"). We also thank Edgardo Cañón-Tapia and an anonymous reviewer for their comments and careful reviews of the previous version of the paper. The editorial work of Malcolm Rutherford and Jürgen W. Neuberg is also appreciated.

\section{References}

Arbaret L., Diot H. \& Launeau P., 1993. Le suc phonolitique du Petit Gerbier (Velay, Massif Central); fabriques magnétiques et magmatique. Comptes Rendus de l'Académie des Sciences, Paris, 316, 2, 1603-1610.

Arbaret, L., Diot, H. and Bouchez, J.L., 1996. Shape fabrics of particles in low concentration suspensions: 2D analogue experiments and application to tiling in magma. J. Struct. Geol. 18 (7), 941-950.

Arbaret, L., Diot, H., Bouchez, J.L., Saint Blanquat, M. and Lespinasse, P., 1997. Analogue 3D simple shear experiments of magmatic biotite subfabric. In: J. L. Bouchez, D. H. W. Hutton and W. E. Stephens (Editors), Granites: from seggregation of melt to emplacement fabrics. Kluwer Academic Publishers, Dordrecht., pp. 129-143.

Arbaret L., Fernandez A., Jezek J., Ildefonse B., Launeau P. and Diot H., 2000. Analogue and numerical modeling of shape fabrics: consequences for strain and flow determination in magmas. Transactions of the Royal Society of Edinburgh: Earth Sciences, 90, 97-109. 
Arbaret L., Mancktelow N.S and Burg J.P., 2001. Shape-preferred orientation and matrix interaction of three-dimensional particles in analogue simple shear flow. J. Struct. Geol., 23, $1,113-125$.

Archanjo, C.J., Launeau, P. and Bouchez, J.L., 1995. Magnetic fabric versus magnetite and biotite shape fabrics of the magnetite-bearing granite pluton of Gameleiras (Northeast Brazil). Phys. Earth Planet. Interiors 89, 63-75.

Aubourg, C., Giordano, G., Mattei, M. and Speranza, F., 2002. Magma flow in sub-aqueous rhyolitic dikes inferred from magnetic fabric analysis (Ponza island, W. Italy). Physics and Chemistry of the Earth 27, 1263-1772.

Aubourg, C., Tshoso, G. Le Gall, B. Bertrand, H., Tiercelin, J.-J., Kampunzu, A.B., Dyment, J. and Modisi, M., 2008. Magma flow revealed by magnetic fabric in the Okavango giant dyke swarm, Karoo igneous province, northern Botswana. Journal of Volcanology an Geothermal Research 170, 247-261.

Bascou, J., Camps, P. and Dautria, J. M., 2005. Magnetic versus crystallographic fabrics in a basaltic lava flow. Journal of Volcanology an Geothermal Research 145, 119-135.

Blanchard, J.P., Boyer, P. and Gagny, C., 1979. Un nouveau critère de sens de mise en place dans une caisse filonienne: Le "pincement" des minéraux aux épontes. Tectonophysics 53, 125 .

Blumenfeld, P. and Bouchez, J.L., 1988. Shear criteria in granite and migmatite deformed in the magmatic and solid states. J. Struct. Geol. 10 (4), 361-372.

Borradaile, G.J., 1988. Magnetic susceptibility, petrofabrics and strain. Tectonophysics 156, $1-20$.

Borradaile, G.J. and Puumala, M.A., 1989. Synthetic magnetic fabrics in a plasticene medium. Tectonophysics 164, 73-78.

Borradaile, G.J., 1991. Correlation of strain with anisotropy of magnetic susceptibility (AMS). Pure Appl. Geophys. 135, 15-29.

Borradaile, G.J., and Werner, T., 1994. Magnetic anisotropy of some phyllosilicates. Tectonophysics 235, 223-248.

Borradaile, G.J., and Henry, B., 1997. Tectonic applications of magnetic susceptibility and its anisotropy. Earth-Science Reviews 42, 49-93. 
Borradaile, G. J. and Gauthier, D., 2003. Emplacement of an Archean gneiss dome, northern Ontario, Canada: Inflation inferred from magnetic fabrics, Tectonics, 22(2), 1011, doi:10.1029/2002TC001443.

Borradaile, G.J., and Jackson, M., 2010. Structural geology, petrofabrics and magnetic fabrics (AMS, AARM, AIRM). Journal of Structural Geology 32, 1519-1551.

Callot, J.-P., Geoffrey, L., Aubourg, C., Pozzi, J.P. and Mege, D., 2001. Magma flow directions of shallow dykes from the East Greenland volcanic margin inferred from magnetic fabric studies. Tectonophysics 335, 313-329.

Cañón-Tapia, E., 2005. Uses of anisotropy of magnetic susceptibility in the study of emplacement processes of lava flows. Geological Society of America Special Paper 396, 2946. doi: 10.1130//2005.2396(03).

Cañón-Tapia, E., 2001. Factors affecting the relative importance of shape and distribution anisotropy in rocks: theory and experiments. Tectonophysics 340, 117-131.

Cañón-Tapia, E., Walker, G. P.L. and Herrero-Bervera, E., 1995. Magnetic fabric and flow direction in basaltic Pahoehoe lava of Xitle Volcano, Mexico. Journal of Volcanology and Geothermal Research 65, 249-263.

Cañón-Tapia, E. and Pinkerton, H., 2000. The anisotropy of magnetic susceptibility of lava flow: an experimental approach. Journal of Volcanology and Geothermal Research 98, 219233.

Cañón-Tapia, E. and Castro, J., 2004. AMS measurement on obsidian from Inyo Domes, CA: a comparison of magnetic and mineral preferred orientation fabrics. Journal of Volcanology and Geothermal Research 134, 169-182.

Cañón-Tapia, E. and Chávez-Álvarez, M.J., 2004. Rotation of uniaxial ellipsoidal particles during simple shear revisited: the influence of elongation ratio, initial distribution of multiparticle system and amount of shear in the acquisition of a stable orientation. Journal of Structural Geology 26, 2073-2087.

Cañón-Tapia, E. and Herrero-Bervera, E., 2009. Sampling strategy and the anisotropy of magnetic susceptibility of dykes. Tectonophysics 466, 3-17.

Cashman, K.V., Thornber, C, Kauahikaua, J.P., 1999. Cooling and crystallization of lava in open channel, and the transition of Pahoehoe lava to 'a'a. Bulletin of Volcanology 61, 306323. 
Cogné, J.P. and Canot-Laurent, S., 1992. Simple shear experiments on magnetized waxhematite samples. Earth Planet. Sci. Lett. 112, 147-159.

Collins, L.R. and Sundaram, S., 1998. Comments on "Particle collision rate in fluid flows". Phys. Fluids 10, 3247-3248.

Debat, P., Sirieys, P., Deramond, J. and Soula, J.C., 1975. Paleodéformations d'un massif orthogneissique (massif des Cammazes, Montagne Noire Occidentale, France). Tectonophysics 28, 159-183.

Dragoni, M., Lanza, R. and Tallarico, A., 1997. Magnetic anisotropy produced by magma flow: theoretical and experimental data from Ferrar dolerite sills (Antartica). Geophysical Journal international 128, 230-240.

Eriksson, P. I., Riishuus, M. S., Sigmundsson, F. and Elming, S.-Å., 2011. Magma flow directions inferred from field evidence and magnetic fabric studies of the Streitishvarf composite dike in east Iceland. Journal of Volcanology and Geothermal Research 206, 30-45.

Ernst, R.E. and Pearce, G.W., 1989. Averaging of anisotropy of magnetic susceptibility data. In: F.P. Agterberg and G.F. Bonham-Carter (Editors), Statistical application in the earth sciences. Geological Survey of Canada paper 89-9, 297-305.

Féménias, O., Diot, H., Berza, T., Gauffriau, A. and Demaiffe, D., 2004. Asymetrical to symetrical magnetic fabric of dikes : Paleo-flow orientations and Paleo-stresses recorded on feeder-bodies from the Motru Dike Swarm (Romania). Journal of Structural Geology 26, 1401-1418.

Fernandez, A.N., Feybesse, J.L. and Mezure, J.F., 1983. Theoretical and experimental study of fabrics developed by different shaped markers in two-dimensional simple shear. Bull. Soc. Géol. Fr. 7, 319-326.

Fernandez, A.N. and Barbarin, B., 1991. Relative rheology of coeval mafic and felsic magmas: nature of resulting interaction processes and shape and mineral fabrics of mafic microgranular enclaves. In: Didier, J. and Barbarin, G. (eds). Enclaves and granite petrology. Elsevier, Amsterdam. 263-275.

Freeman, B., 1985. The motion of rigid ellipsoidal particles in slow flows. Tectonophysics $113,163-183$. 
Gaillot, P., de Saint Blaquat, M. and Bouchez, J.-L., 2006. Effects of magnetic interactions in anisotropy of magnetic susceptibility: models, experiments and implications for igneous rock fabrics quantification. Tectonophysics 418, 3-19.

Gay, N.C., 1968. Pure shear and simple shear deformation of inhomogeneous viscous fluids. 1. Theory. Tectonophysics 5, 211-234.

Geoffroy, L., Callot, J. P., Aubourg, C. and Moriera, M., 2002. Magnetic and plagioclase linear fabric discrepancy in dykes: a new way to define the flow vector using magnetic foliation. Terra Nova 14, 1-8.

Grégoire, V., de Saint Blaquat, Nédélec, A. and Bouchez, J.-L., 1995. Shape anisotropy versus magnetic interactions of magnetite grains : experiments and application to AMS in ganitic rocks. Geophysical Research Letters 22, 276-2768.

Grégoire, V., Darrozes, J., Gaillot, P., Nédélec, A. and Launeau, P., 1998. Magnetite grain shape fabric and distribution anisotropy vs rock magnetic fabric: a three-dimensional case study. J. Struct. Geol. 20 (7), 937-944.

Hargraves, R. B., Johnson, D. and Chan, C. Y., 1991. Distribution anisotropy: the cause of AMS in igneous rocks? Geophysical Research Letters 18, 2193-2196.

Harvey, P.K. and Laxton, R.R., 1980. The estimation of finite strain from orientation distribution of passively deformed linear markers: eigenvalue relationship. Tectonophysics $70,285-307$.

Hastie, W. W., Watkeys, M. K. and Aubourg, C., 2011. Significance of magnetic and petrofabric in Karoo-feeder dykes, northern Lebombo. Tectonophysics 513, 96-111.

Hrouda, F., 1982. Magnetic anisotopy of rocks and its application in geology and geophysics. Geophys. Surveys 5, 37-82.

Hrouda, D. and Ježek, J., 1999. Theoretical models of magnetic anisotropy to strain relationship: effect of triaxial magnetic grains. Tectonophysics 301, 183-190.

Hu, K.C. and Mei, R., 1998. Particle collision rate in fluid flows. Phys. Fluids 10, 1028-1030.

Ildefonse, B., Sokoutis, D. and Mancktelow, N.S., 1992. Mechanical interactions between rigid particles in a deforming ductile matrix. Analogue experiments in simple shear flow. J. Struct. Geol. 14 (10), 1253-1266. 
Ildefonse, B., and Mancktelow, N.S., 1993. Deformation around rigid particles: the influence of slip at the particle/matrix interface. Tectonophysics 221, 345-359.

Ildefonse, B., Arbaret, L. and Diot, H., 1997. Rigid particles in simple shear flow: is their preferred orientation periodic or steady state ? In: J. L. Bouchez, D. H. W. Hutton and W. E. Stephens (Editors), Granites: from seggregation of melt to emplacement fabrics. Kluwer Academic Publishers, Dordrecht, pp. 177-185.

Jeffery, G.B., 1922. The motion of ellipsoidal particles immersed in a viscous fluid. Proc. R. Soc. London 102, 201-211.

Jelinek, V., 1981. Characterization of the magmatic fabrics of rocks. Tectonophysics 79, 6367.

Ježek, J., 1994. Sofware for modeling the motion of rigid triaxial ellipsoidal particles in viscous flow. Computers and Geosciences 20, 409-424.

Ježek, J., Melka, R., Schulmann, K. and Venera, Z., 1994. The behaviour of rigid triaxial particles in viscous flows-modelling of fabric evolution in a multiparticle system. Tectonophysics 229, 165-180.

Ježek, J., Schulmann, K. and Segeth, K., 1996. Fabric evolution of rigid inclusions during mixed coaxial and simple shear flows. Tectonophysics 257, 203-221.

Launeau, P. and Cruden, A.R., 1998. Magmatic fabric acquisition mechanism in a syenite: Results of a combined anisotropy of magnetic susceptibility and image analysis study. Journal of Geophysical Research 103, 5067-5089.

Launeau, P., 2004. Evidence of magmatic flow by 2-D image analysis of 3-D shape preferred orientation distributions. Bulletin de la Société Géologique de France 175, 331-350.

Launeau, P. and Robin, P.-Y., 2005. Determination of fabric ellipsoids from measured sectional ellipses - implementation and applications. Journal of Structural Geology 27, 22232233.

Loock, S., Diot, H., Van Wyk de Vries, B., Launeau, P., Merle, O., Vadeboin, F. and Petronis, M. S., 2008. Lava flow internal structure found from AMS and textural data: an example in methodology from the Chaîne des Puys, France. Journal of Volcanology and Geothermal Research 177, 1092-1104. 
Mancktelow N.S, Arbaret L. and Pennacchioni G., 2002. Experimental observations on the effect of interface slip on rotation and stabilisation of rigid particles in simple shear and a comparison with natural mylonites. Journal of Structural Geology, 24, 567-585.

March, A., 1932. Mathematische theory der regelung nach der korngestalt bei affiner deformation. Zeitschr. f. Kristallogr. 81, 285-297.

Marques, F.O., Taborda, R. and Antunes, J., 2005a. Influence of a low-viscosity layer between rigid inclusion and viscous matrix on inclusion rotation and matrix flow: a numerical study. Tectonophysics 407, 101-115.

Marques, F.O., Taborda, R. and Antunes, J., 2005b. 2D rotation of rigid inclusions in confined bulk simple shear flow : a numerical study.

Marsh, B.D., 1988. Crystal size distribution (CSD) in rocks and the kinematics and dynamics of crystallization; 1. Theory. Contrib. Mineral. Petrol. 99, 277-291. Journal of Structural Geology 27, 2171-2180.

Merle, O., 1998. Internal strain within lava flows from analogue modelling. Journal of Volcanology and Geothermal Research 81, 189-206.

Owens, W. H., 1984. The calculation of a best-fit ellipsoid from elliptical sections on arbitrarily oriented planes. Journal of Structural Geology 6, 571-578.

Petford, N., 2003. Rheology of granitic magmas during ascent and emplacement. An. Rev. Earth Planet. Sci., 31, 399-427.

Philpotts, A. R., and Asher, P. M., 1994. Magmatic flow-direction indicators in a giant diabase feeder dike. Geology, 22, 363-366.

Philpotts, A. R. and Philpotts, D. E., 2007. Upward and downward flow in a camptonite dike as recorded by deformed vesicles and the anisotropy of magnetic susceptibility (AMS). Journal of Volcanology and Geothermal Research 161, 81-94.

Poland, M. P., Fink, J. H. and Tauxe, L., 2004. Pattern of magma flow in segmented silicic dikes at Summer Coon volcano, Colorado: AMS and thin section analysis. Earth and Planetary Science Letter 219, 155-169.

Reed, L.J. and Tryggvason, E., 1974. Preferred orientation of rigid particles in a viscous matrix deformed by pure shear and simple shear. Tectonophysics $24,85-98$. 
Rees, A.I., 1968. The production of preferred orientation in a concentrated dispersion of elongated and flattened grains. Journal of Geology 76, 457-465.

Rees, A.I., 1979. The orientation of grains in a sheared dispersion. Tectonophysics 55, 275287.

Robin, P.-Y., 2002. Determination of fabric and strain ellipsoids from measured sectional ellipses - theory. Journal of Structural Geology 24, 531-544.

Rochette, P., Jackson, M. and Aubourg, C., 1992. Rock magnetism and the interpretation of anisotropy of magnetic susceptibility. Rev. Geophys. 30, 209-226.

Rochette, P., Aubourg, C., Perrin, M., 1999. Is this magnetic fabric normal? A review and case studies in volcanic formations. Tectonophysics 307, 219-234.

Shimamoto, T. and Ikeda, Y., 1976. A simple algebraic method for strain estimation from deformed ellipsoidal objects. 1. Basic theory. Tectonophysics 36, 315-337.

Sundaram, S. and Collins, L. R., 1997. Collision statistics in an isotropic, particle laden turbulent suspension i. Direct numerical simulation. J. Fluid Mech. 335, 75.

Tarling, D.H. and Hrouda, F., 1993. The magnetic anisotropy of rocks. Chapman and Hall, New York, 217 p.

Tauxe, L., Gee, J. S., Staudigel, H., 1998. Flows directions in dikes from anisotropy of magnetic susceptibility data: The bootstrap way. Journal of Geophysical Research 103, $17,775-17,790$.

Tikoff, B. and Teyssier, C., 1994. Strain and fabric analyses based on porphyroclast interaction. J. of Struct. Geol. 16 (4), 477-491.

Wang, L.-P., Wexler, A.S. and Zhou, Y., 1998. On the collision rate of small particles in isotropic turbulence. 1. Zero-inertia case. Phys. Fluids 10, 266-276.

Yamato, P., Tertèse, R., Duretz, T., May, D.A., 2011. Numerical modelling of magma transport in dykes. Tectonophysics, doi:10.1016/j.tecto.2011.05.015. 


\section{Fig. caption}

Fig. 1. a - Sketch of the experimental setup. XYZ is the external fixed reference frame with $\mathrm{XY}$ the plane of undisturbed shear flow and $\mathrm{X}$ the direction of shear. $\mathrm{b}-\mathrm{Six}$ cores are regularly drilled in the magnetite suspension frozen after experiment. The arrow is parallel to X. c - A large sample is extracted after experiment in which three sections are cut parallel to the three main planes of the finite strain ellipsoid. $\rho$ correspond to the angle between $\mathrm{Y}$ and the finite strain main axe.

Fig. 2. XZ section of $1 \%$ volume fraction magnetite suspension at the initial, undeformed stage. Note that the subjacent particles appear as light grey objects due to the semitransparency of the matrix. They are not taken into account for image analysis applied to one plane.

Fig. 3. a - Distribution of aspect ratios of 5069 magnetite grains measured in 30 sections randomly oriented in the starting material. $b$ - Distribution of aspect ratios of 800 particles selected from two sections, used for simulation.

Fig. 4. Lower hemisphere equal area projections of the evolution of AMS (Black dots) and shape (white dots) fabrics with increasing shear strain $\gamma$. Associated diagrams: symmetry $T$ and eccentricity $P$ defining the shape of the AMS (Dark dots) and SPO ellipsoids (White dots).

Fig. 5. Numerical simulation of the evolution with increasing shear strain $\gamma$ of a population formed by 800 particles (Black dots), having an homogeneous aspect ratio of 1.71, represented in lower hemisphere equal area projections. Black great circle represent the average foliation and the white square is the lineation. Grey surfaces represents the standard deviation on the average orientation of the lineation.

Fig. 6. Numerical simulation of the evolution with increasing shear strain $\gamma$ of a population formed by 800 particles (Black dots), having normal log distributed aspect ratios (see 
distribution in fig. 3b), represented in lower hemisphere equal area projections. Black great circle represent the average foliation and the white square is the lineation. Grey surfaces represents the standard deviation on the average orientation of the lineation.

Fig. 7. a: Numerical simulation of the evolution with increasing shear strain $\gamma$ of a population formed by 800 particles (black triangles), having normal log distributed aspect ratios (see distribution in fig. 3b, and particular steps in fig. 6), and compared to the theoretical orbit for homogeneously shaped population of particles . Lower hemisphere equal area projections. b: Eccentricity $P_{s}$ versus symmetry $T_{s}$ with increasing simple shear deformation $(0<\gamma<20)$ for the homogenously shaped population of particles (evolution of the orientations in fig. 5) and the population of particles with normal log distributed aspect ratios (black triangles, evolution of the orientations in fig. 6 and in b).

Fig. 8. Comparison between experimental SPO and AMS results (dashed lines), twodimensional evolution of shape fabric intensity $I$ and orientation $\alpha$ of theoretical homogeneously shaped population of particles $(R=1.71$, Grey curves) and 10 simulations using the aspect ratio distribution of particles of magnetite with different random initial orientations (800 particles, black curves). Step of calculation: $0.1 \gamma$. See text for explanations on numbered simulations.

Fig. 9. Cumulated percentage $C \%$ of collided particles versus shear strain $\gamma$ in a solid suspension with $1 \%$ volume of particles, $75 \mu \mathrm{m}$ in diameter. Inset diagram: Evolution of the collision rate $N_{c}$ as a function of the number of particles $N$.

Fig. 10. Strain span of collision $\gamma_{s p}$ between two colliding particles as a function of their aspect ratio $\xi$ calculated from two-dimensional experiments on tiling development performed at a constant strain rate.

Fig. 11. Simplified two-dimensional model of the evolution of a shape fabric developed in a low concentration suspensions of solid particles embedded in a viscous fluid during simple shear regime. The first, low strains, stage is controlled by the rotation of particles as predicted 
by the model of Jeffery (1922). The second, large strains, stage is characterised by irregularly oscillating to quasi-steady state fabrics produced by the combined influence of nonhomogeneous aspect ratios and initial orientations of the particles and, for the largest strains, by contact interactions between solid particles. 

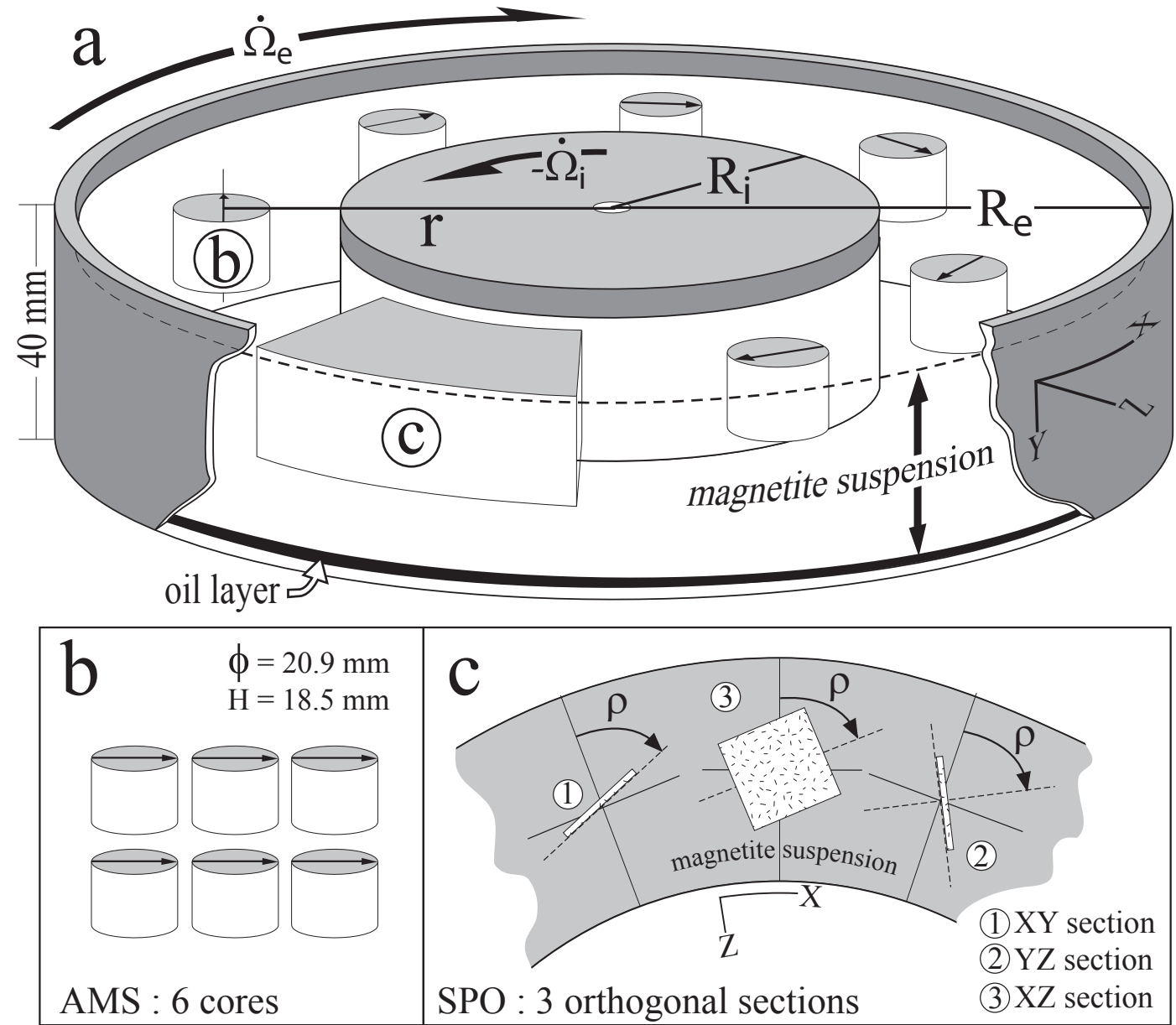


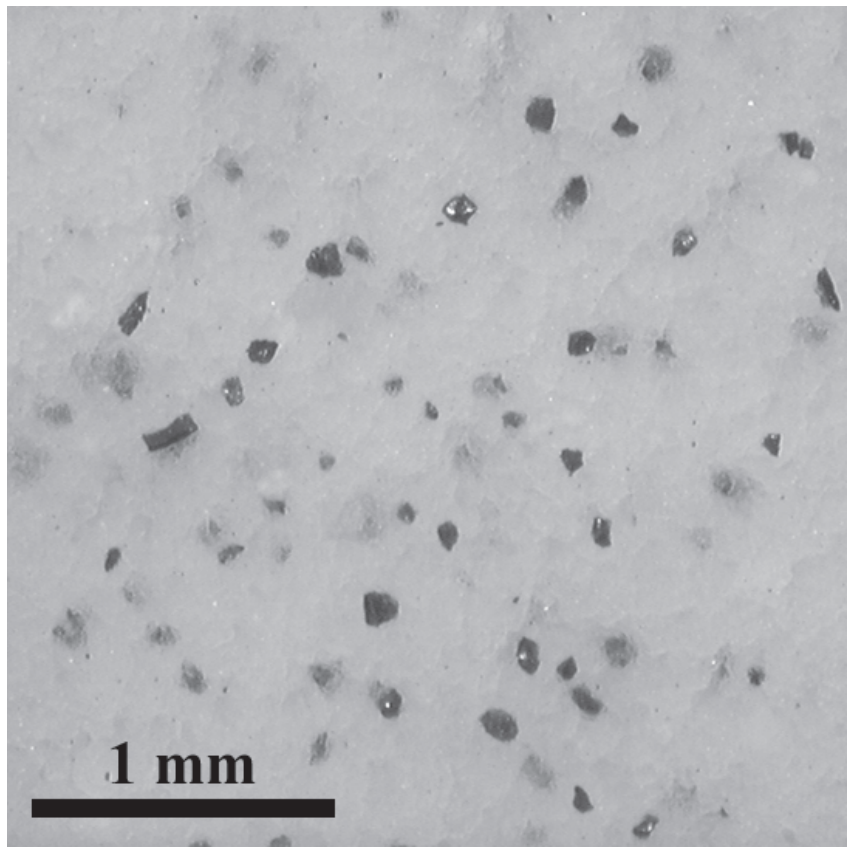



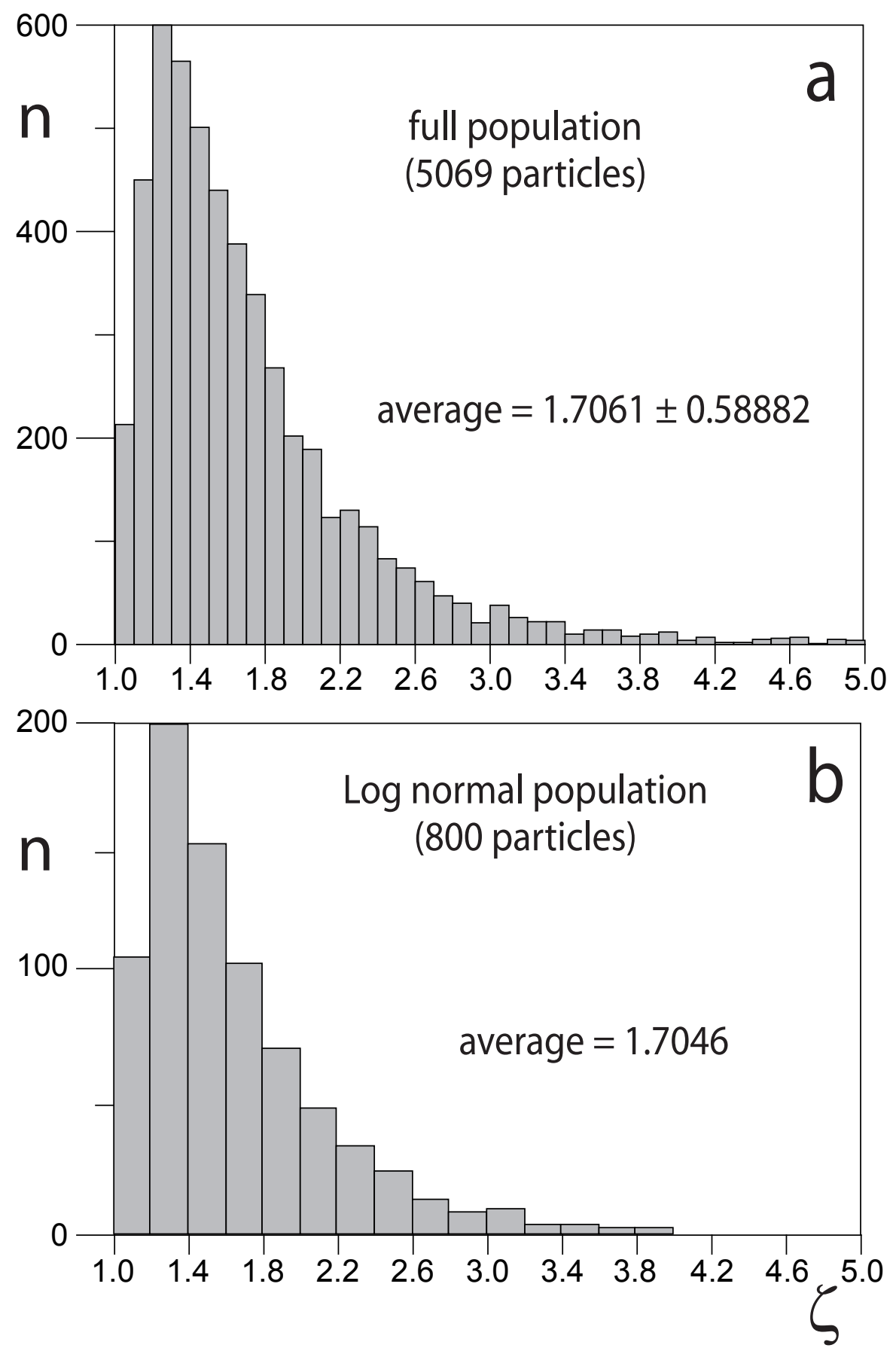


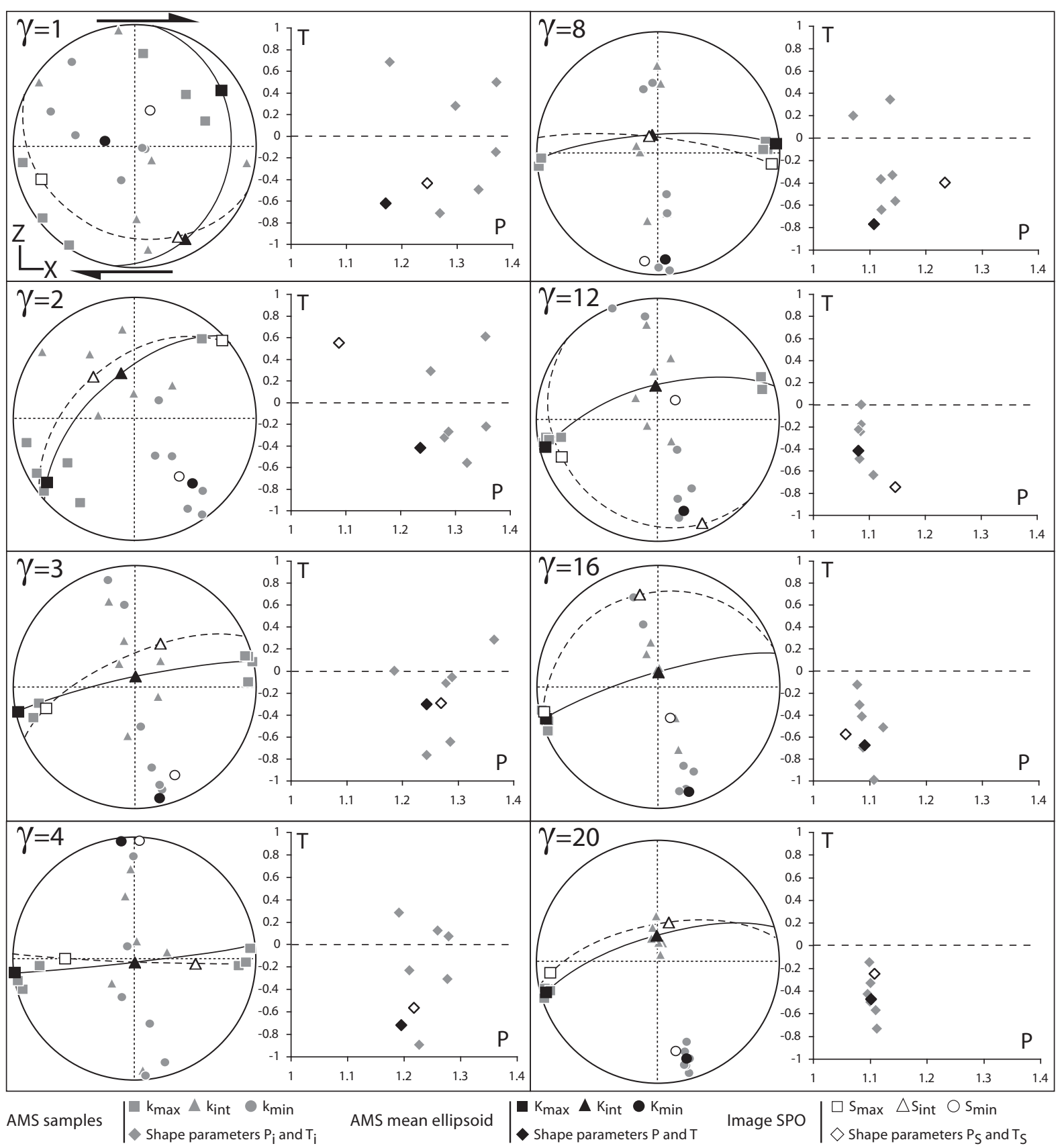




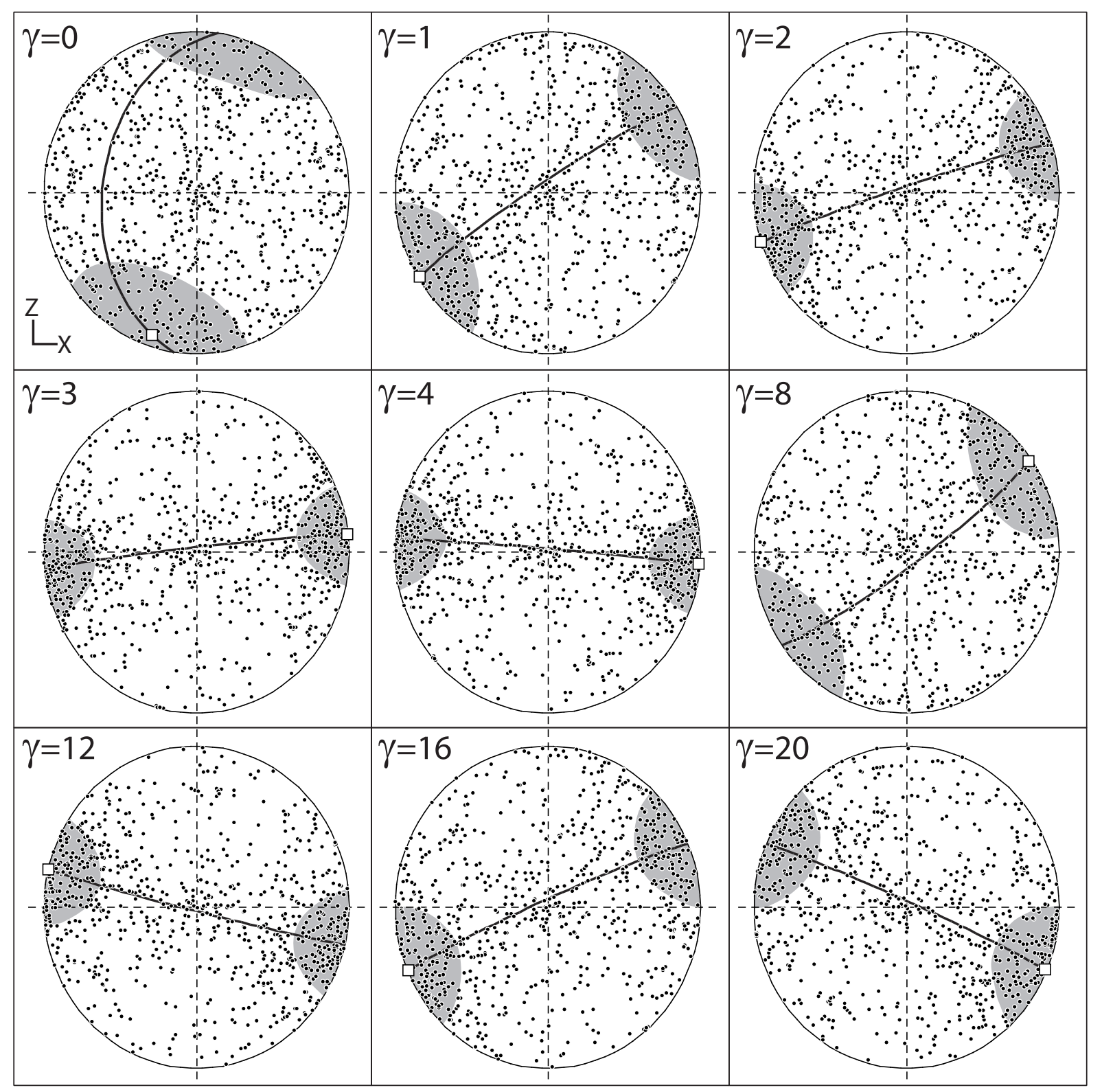




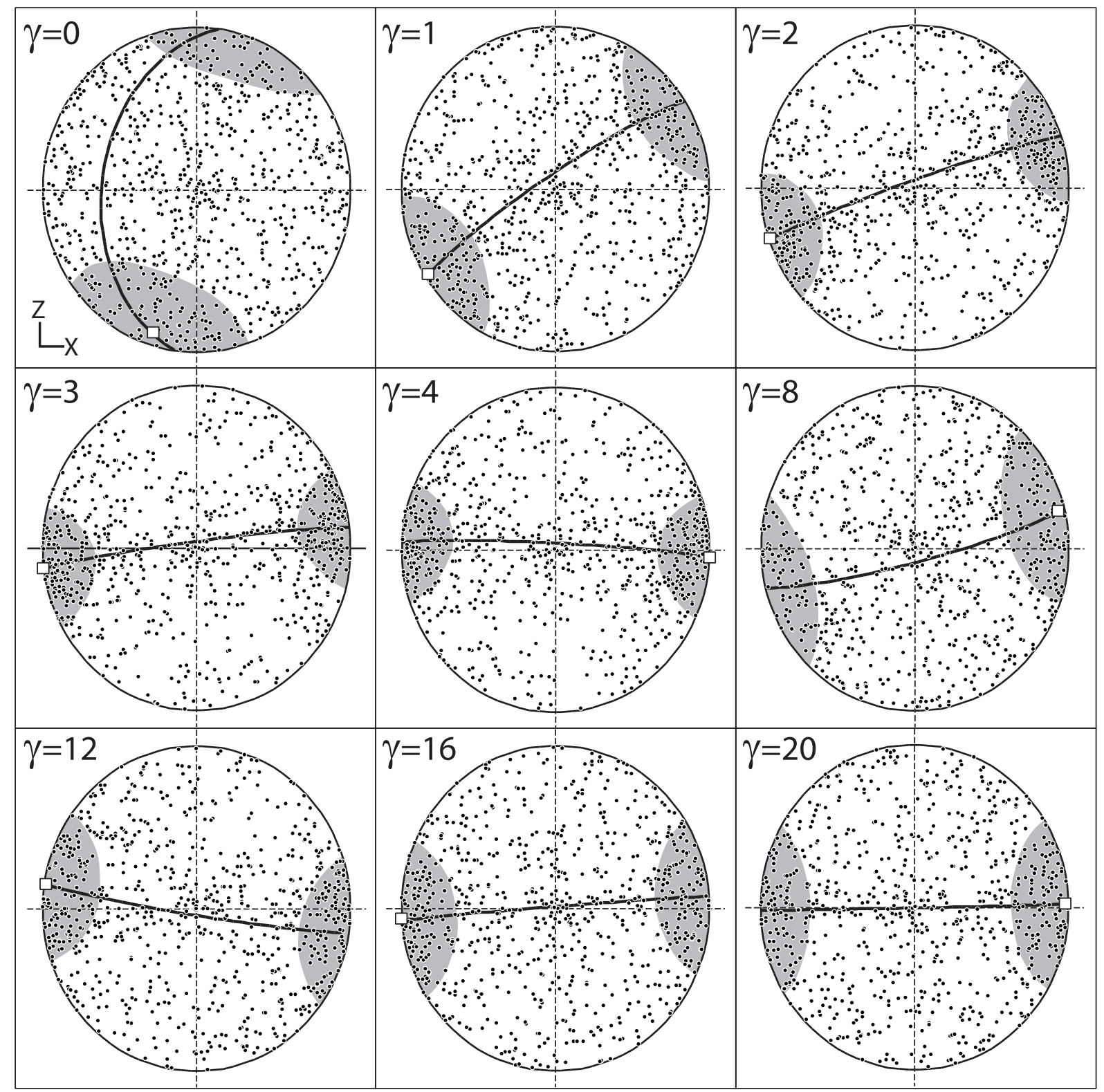



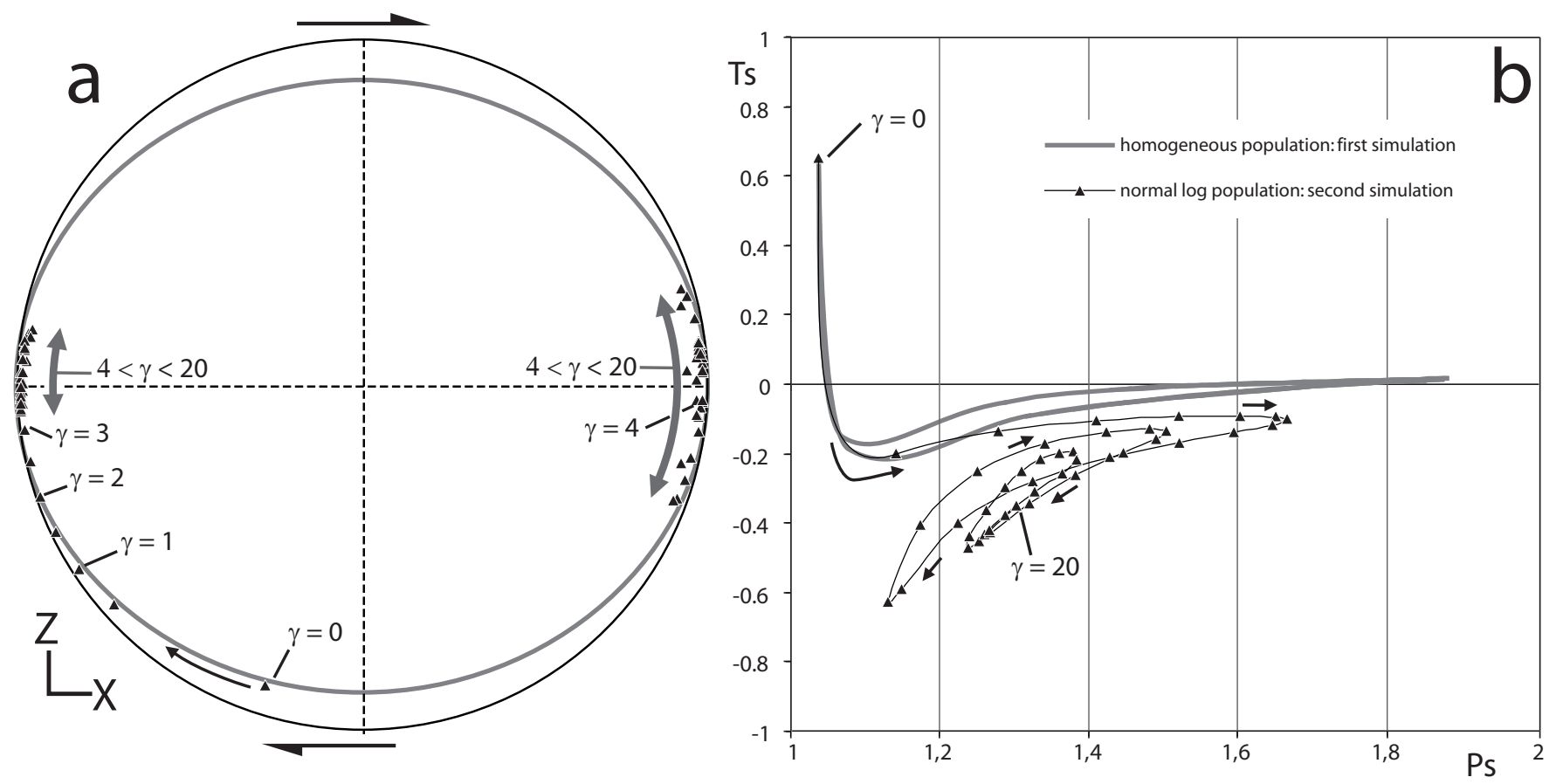


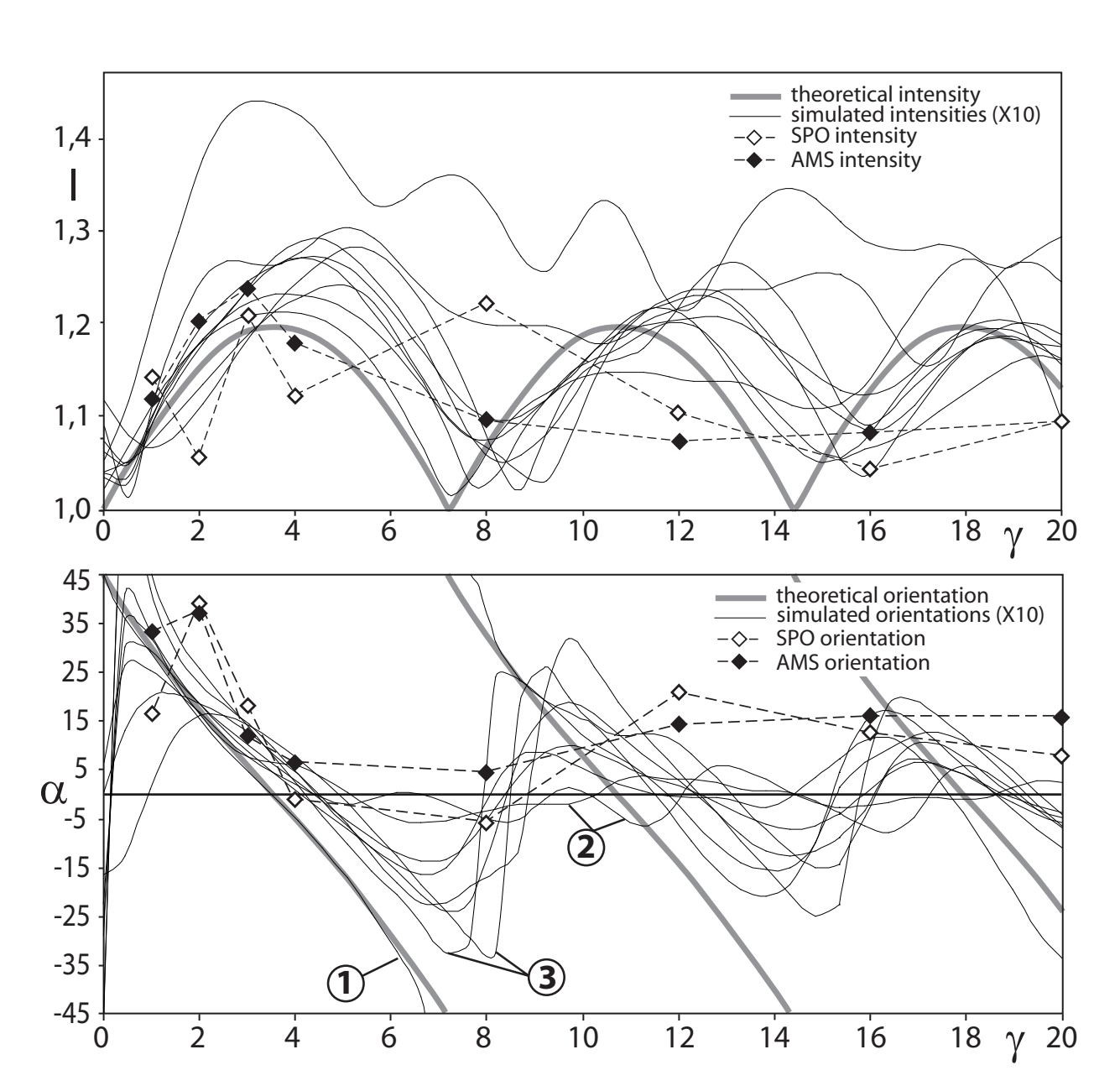




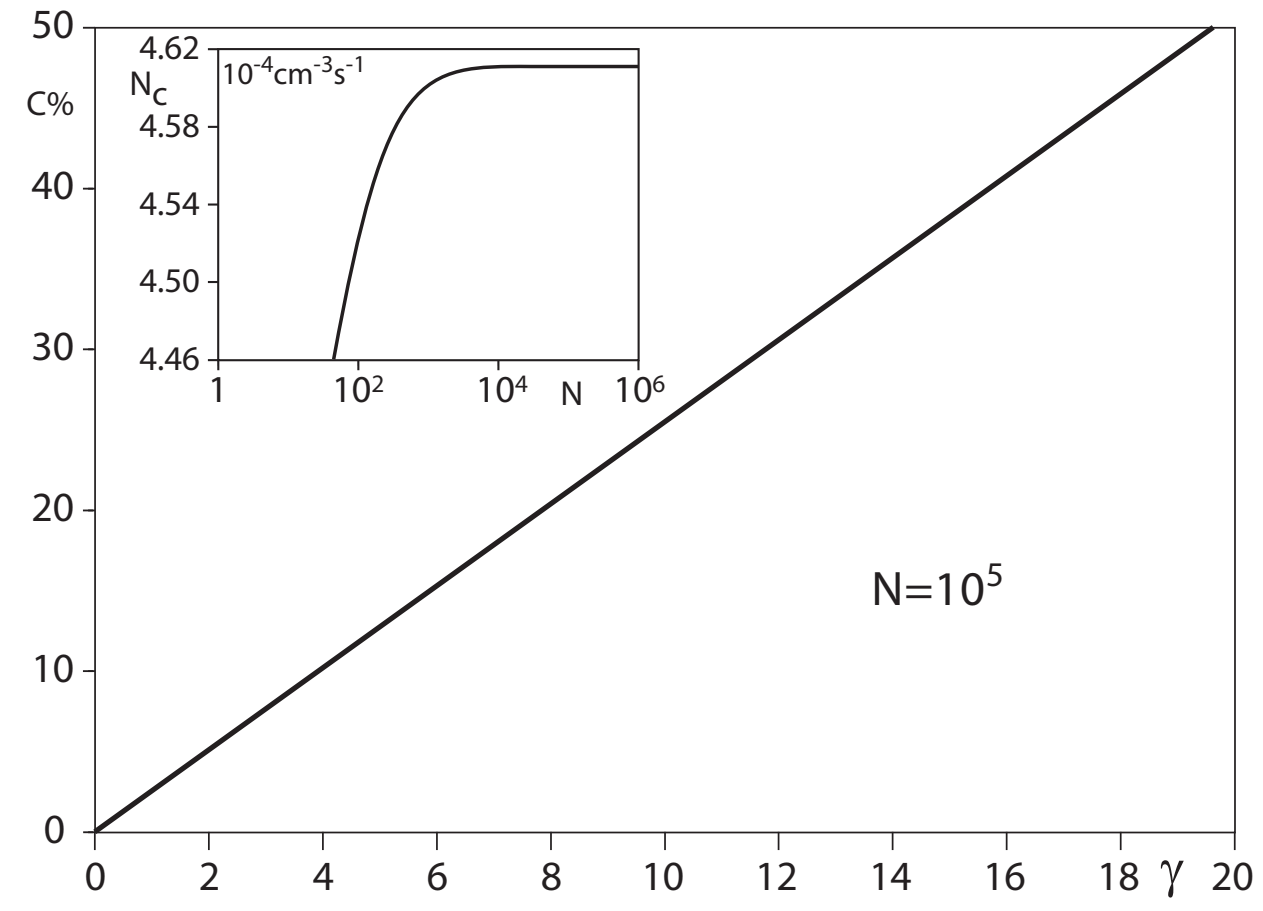




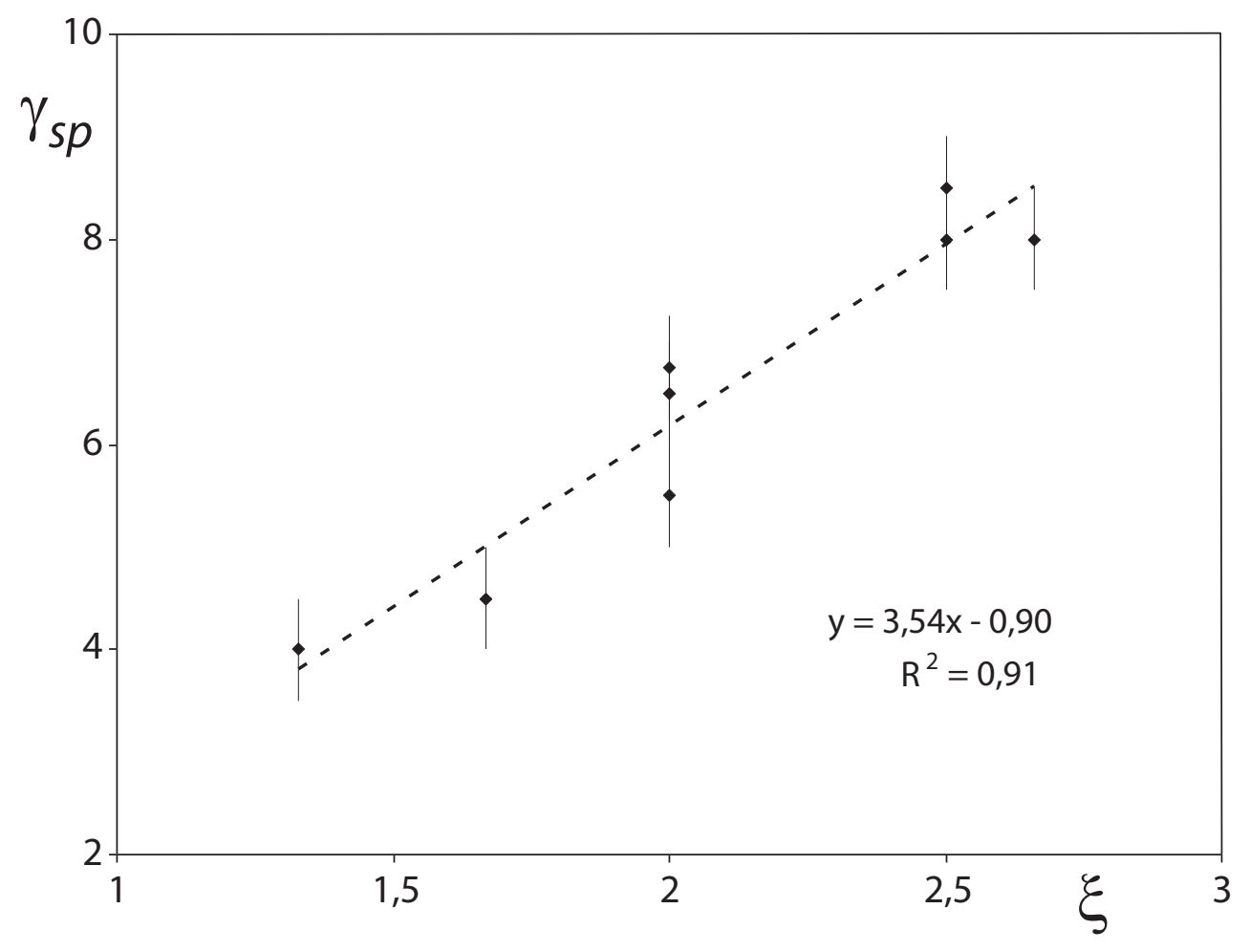




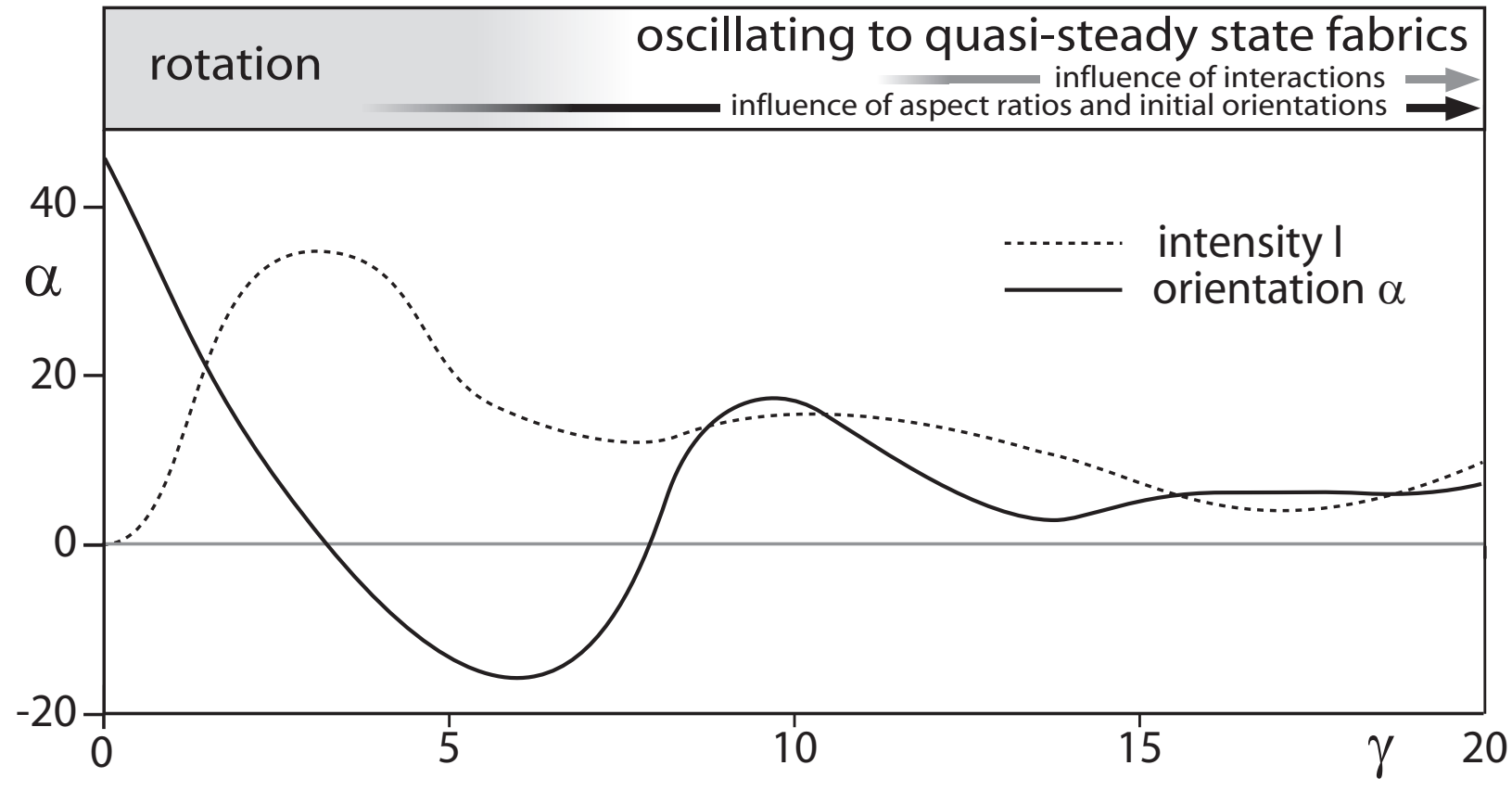

